\title{
Bromophenols Coupled with Methyl $\gamma$-Ureidobuty- rate and Bromophenol Sulfates from the Red Alga Rhodomela confervoides
}

Ming Ma ${ }^{\dagger}$ Jielu Zhao, ${ }^{\dagger}$ Sujuan Wang, ${ }^{\dagger}$ Shuai $\mathrm{Li},{ }^{\dagger}$ Yongchun Yang, ${ }^{\dagger}$ Jiangong Shi, ${ }^{\dagger}, *$ Xiao Fan, ${ }^{\dagger} * *$ and Lan $\mathrm{He}^{\S, *}$

Institute of Materia Medica, Chinese Academy of Medical Sciences and Peking Union Medical College, Beijing 100050, People's Republic of China, Institute of Oceanology, Chinese Academy of Sciences, Qingdao 266071, People's Republic of China, Department of Chemistry, Beijing Normal University, Beijing 100875, People's Republic of China

\section{List of Supporting Information}

\begin{tabular}{|c|c|c|}
\hline No. & Content & pages \\
\hline 1 & FABMS of Compound 1 & 3 \\
\hline 2 & ${ }^{1} \mathrm{H}$ NMR Spectrum of compound 1 & 4 \\
\hline 3 & ${ }^{13} \mathrm{C}$ NMR Spectrum of compound 1 & 5 \\
\hline 4 & DEPT Spectrum of compound 1 & 6 \\
\hline 5 & ${ }^{1} \mathrm{H}-{ }^{1} \mathrm{H}$ COSY Spectrum of compound 1 & 7 \\
\hline 6 & g HMQC Spectrum of compound 1 & 8 \\
\hline 7 & gHMBC Spectrum of compound 1 & 9 \\
\hline 8 & FABMS of Compound 2 & 10 \\
\hline 9 & ${ }^{1}$ H NMR Spectrum of compound 2 & 11 \\
\hline 10 & ${ }^{13} \mathrm{C}$ NMR Spectrum of compound 2 & 12 \\
\hline 11 & DEPT Spectrum of compound 2 & 13 \\
\hline 12 & ${ }^{1} \mathrm{H}-{ }^{1} \mathrm{H}$ COSY Spectrum of compound 2 & 14 \\
\hline 13 & GHMQC Spectrum of compound 2 & 15 \\
\hline 14 & gHMBC Spectrum of compound 2 & 16 \\
\hline 15 & FABMS of Compound 3 & 17 \\
\hline 16 & ${ }^{1}$ H NMR Spectrum of compound 3 & 18 \\
\hline 17 & ${ }^{13} \mathrm{C}$ NMR Spectrum of compound 3 & 19 \\
\hline 18 & DEPT Spectrum of compound 3 & 20 \\
\hline 19 & ${ }^{1} \mathrm{H}-{ }^{1} \mathrm{H}$ COSY Spectrum of compound 3 & 21 \\
\hline 20 & GHMQC Spectrum of compound 3 & 22 \\
\hline 21 & gHMBC Spectrum of compound 3 & 23 \\
\hline 22 & FABMS of Compound 4 & 24 \\
\hline 23 & FABMS of Compound 4 (Regional Expended) & 25 \\
\hline
\end{tabular}




\begin{tabular}{|l|l|l|}
\hline 24 & ${ }^{1}$ H NMR Spectrum of compound 4 & 26 \\
\hline 25 & ${ }^{13}$ C NMR Spectrum of compound 4 & 27 \\
\hline 26 & DEPT Spectrum of compound 4 & 28 \\
\hline 27 & ${ }^{1}$ H- ${ }^{1}$ H COSY Spectrum of compound 4 & 29 \\
\hline 28 & gHMQC Spectrum of compound 4 & 30 \\
\hline 29 & gHMBC Spectrum of compound 4 & 31 \\
\hline 30 & EIMS of Compound 5 & 32 \\
\hline 31 & ${ }^{1}$ H NMR Spectrum of compound 5 & 33 \\
\hline 32 & ${ }^{13}$ C NMR Spectrum of compound 5 & 34 \\
\hline 33 & gHMBC Spectrum of compound 5 & 35 \\
\hline 34 & ESIMS of compound 6 & 36 \\
\hline 35 & ${ }^{1}$ H NMR Spectrum of compound 6 & 37 \\
\hline 36 & ${ }^{13}$ C NMR Spectrum of compound 6 & 38 \\
\hline 37 & DEPT Spectrum of compound 6 & 39 \\
\hline 38 & gHMBC Spectrum of compound 6 & 40 \\
\hline 39 & ESIMS of compound 7 & 41 \\
\hline 40 & ${ }^{1}$ H NMR Spectrum of compound 7 & 42 \\
\hline 41 & ${ }^{13}$ C NMR Spectrum of compound 7 & 43 \\
\hline 42 & DEPT Spectrum of compound 7 & 44 \\
\hline 43 & gHMBC Spectrum of compound 7 & 45 \\
\hline 44 & ESIMS of compound 8 & 46 \\
\hline 45 & ${ }^{1}$ H NMR Spectrum of compound 8 & 47 \\
\hline 46 & ${ }^{13}$ C NMR Spectrum of compound 8 & 48 \\
\hline 47 & DEPT Spectrum of compound 8 & 49 \\
\hline 48 & gHMBC Spectrum of compound 8 & 50 \\
\hline & & \\
\hline
\end{tabular}




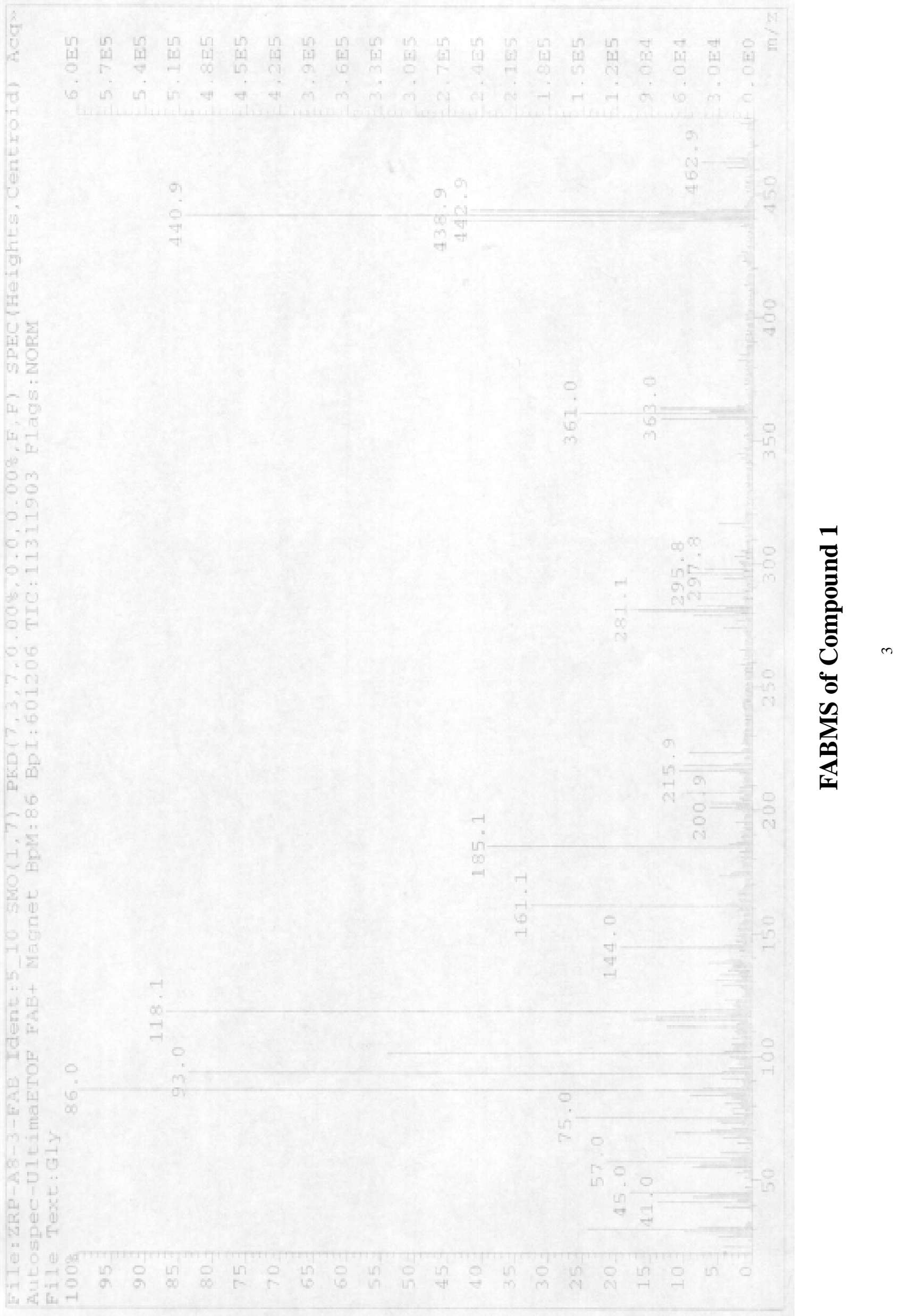




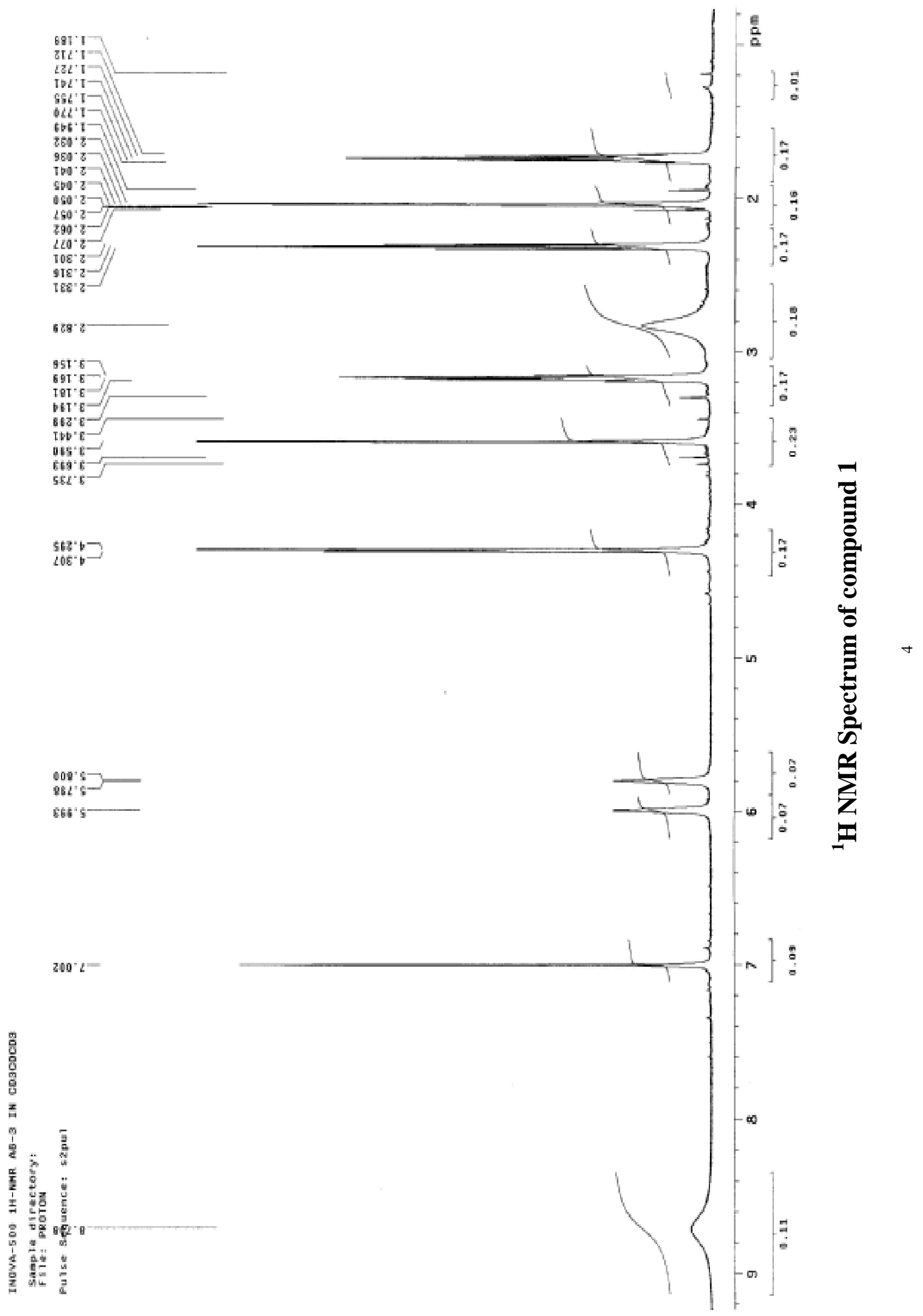




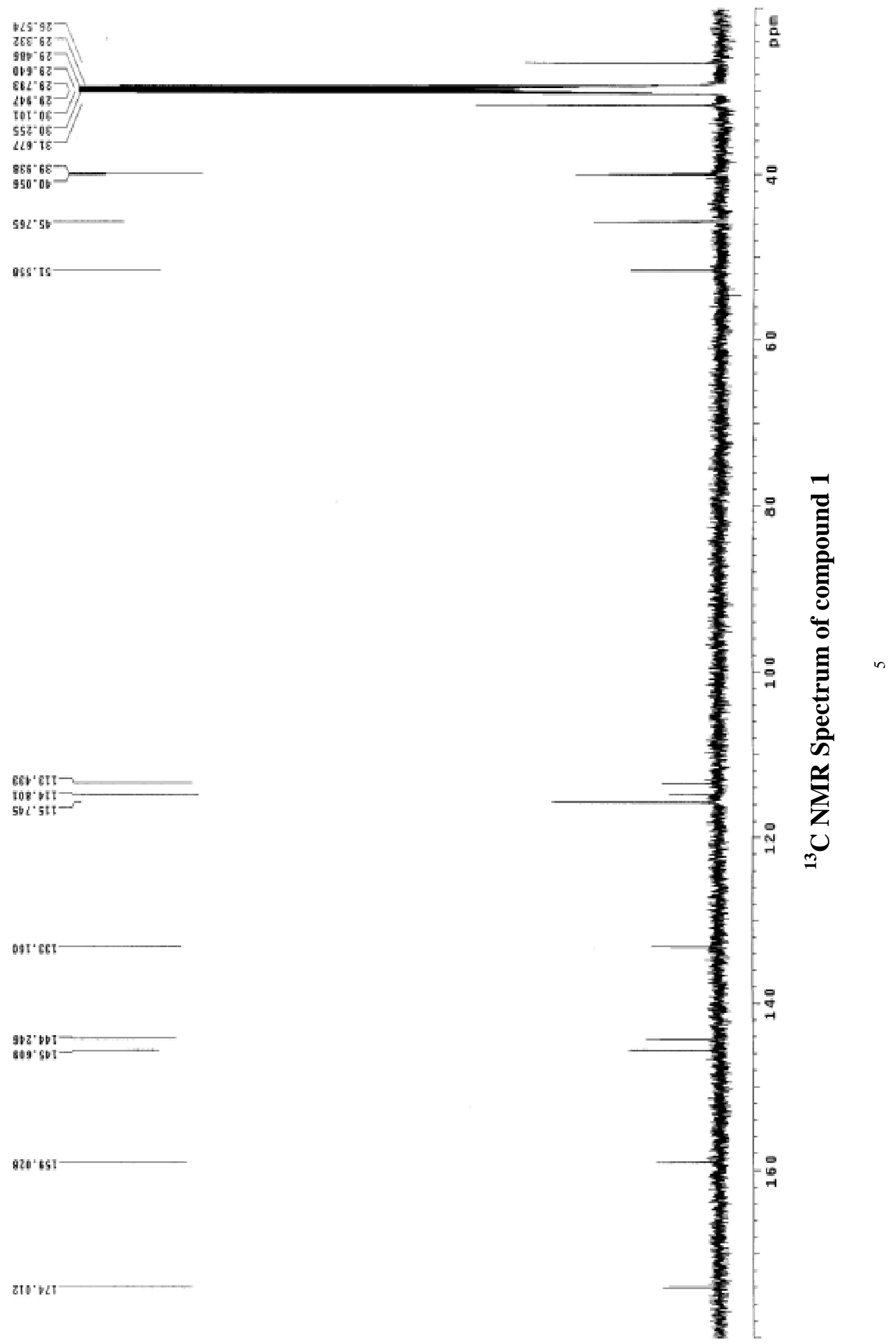




$$
1
$$



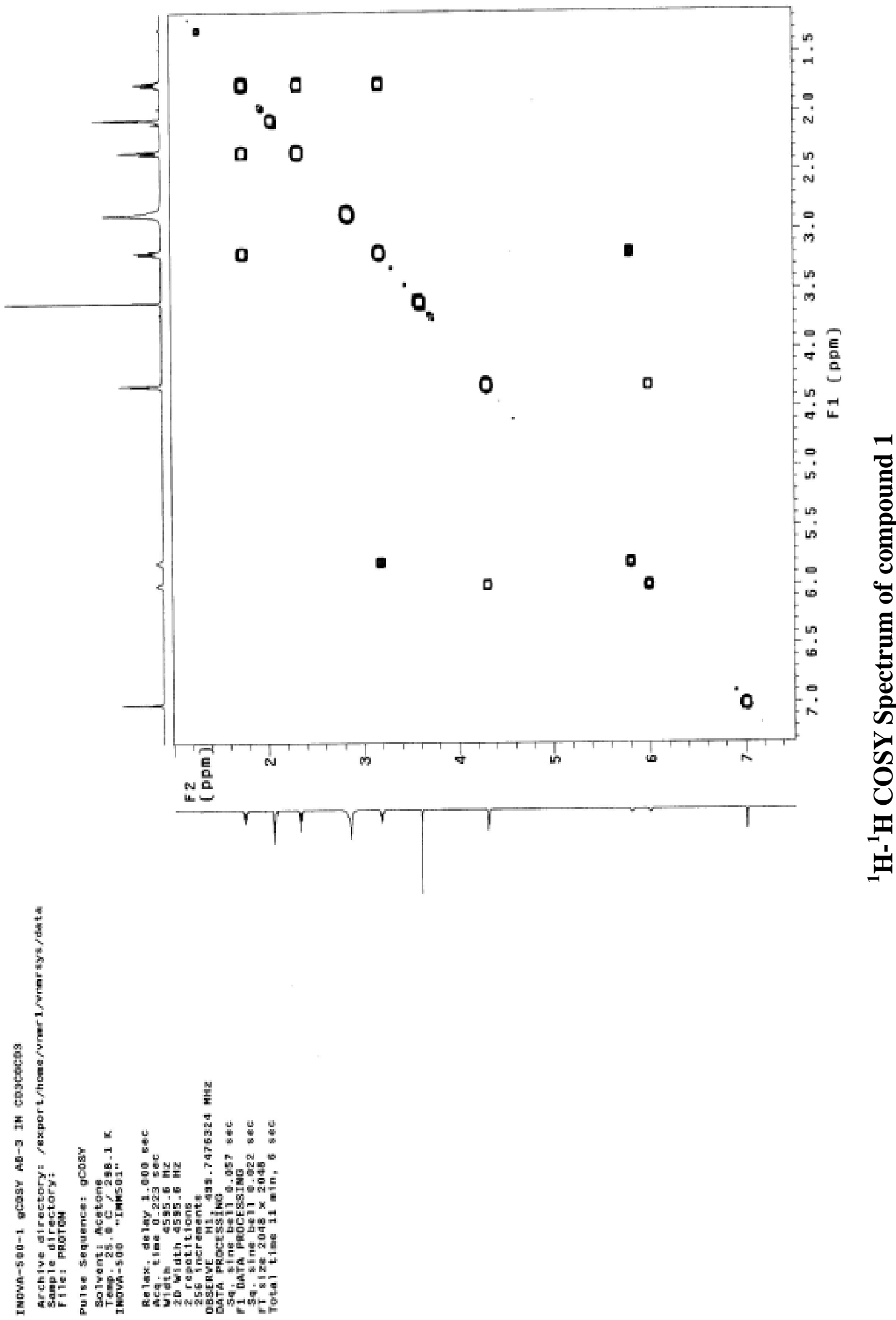


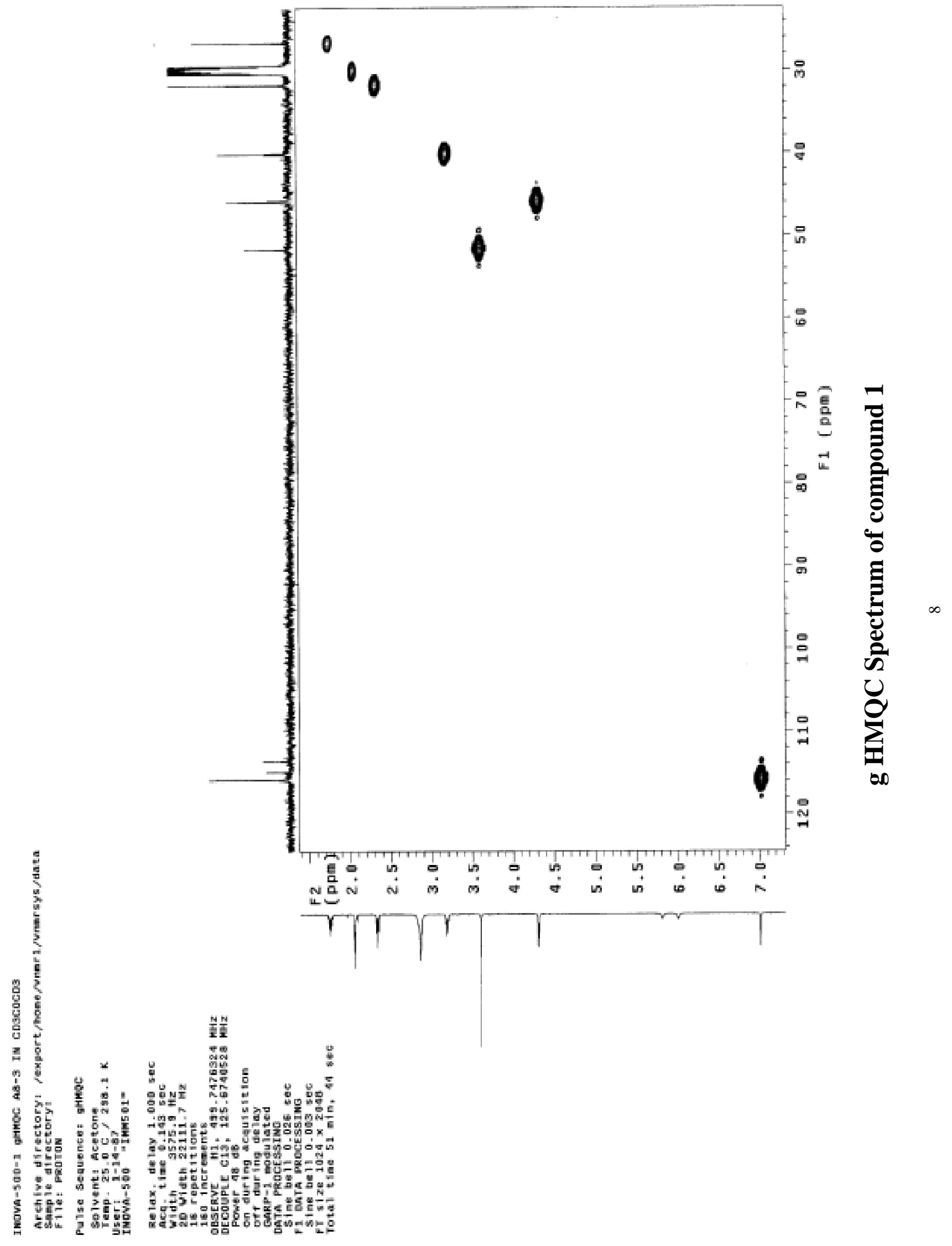


00

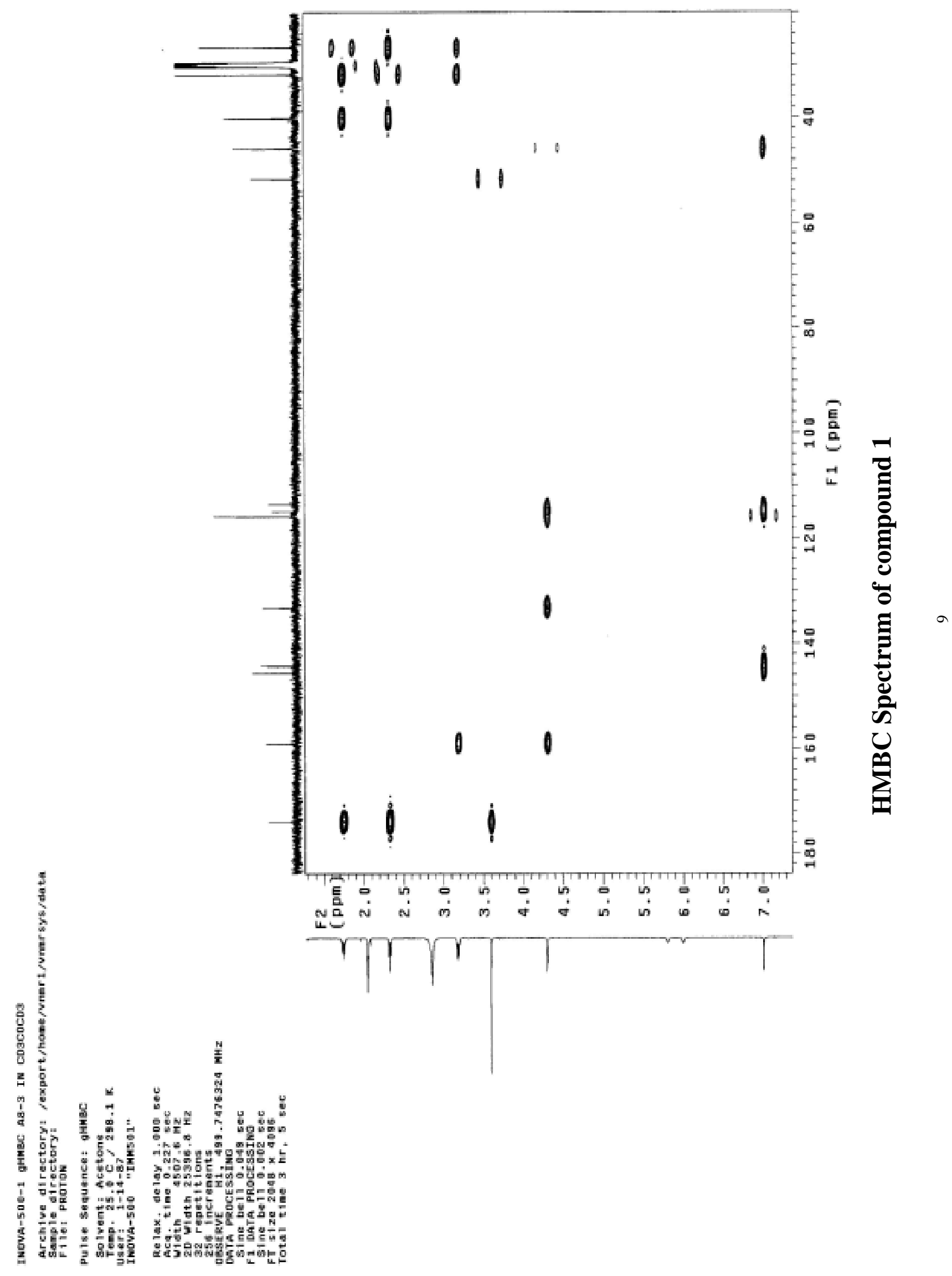




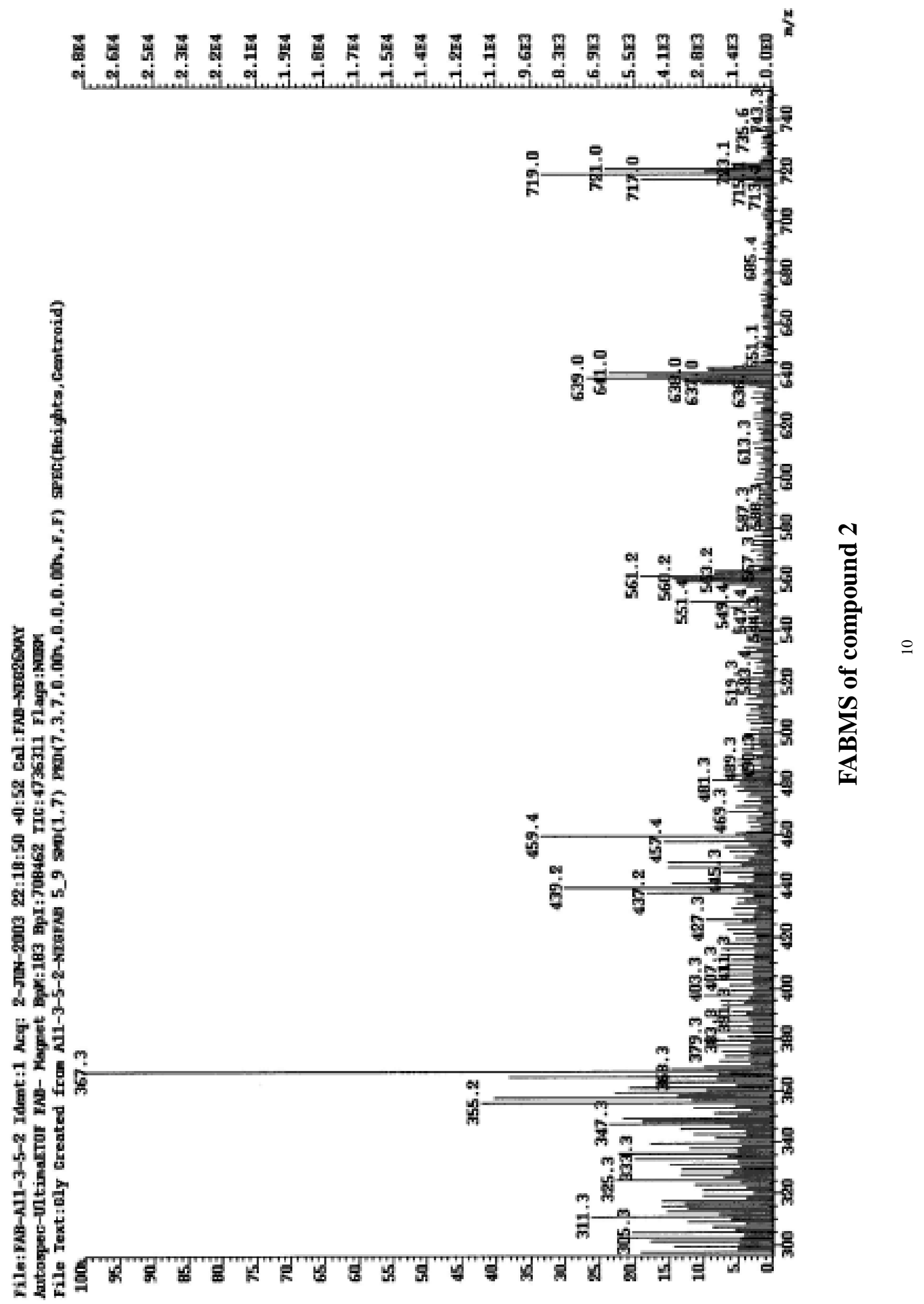




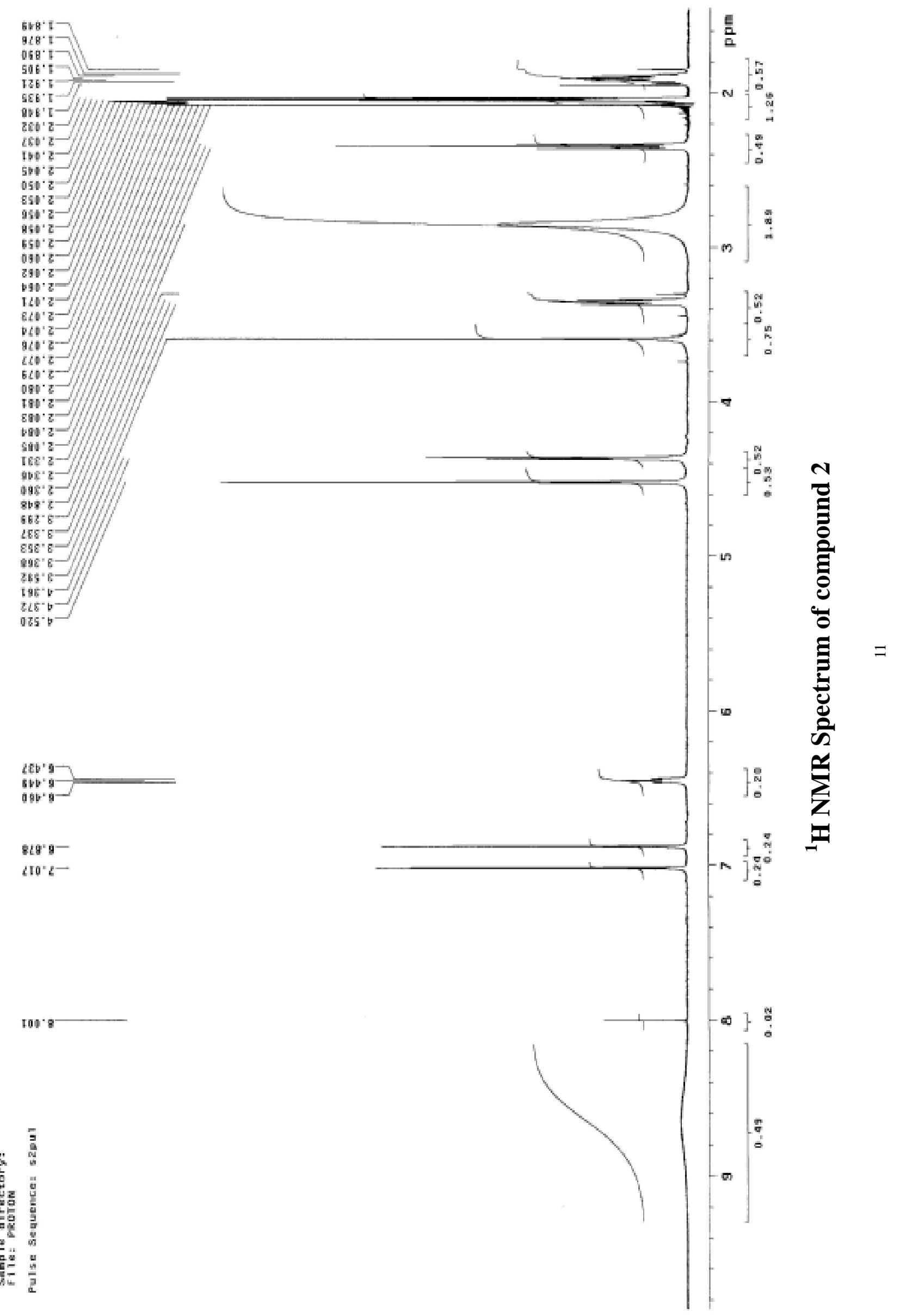




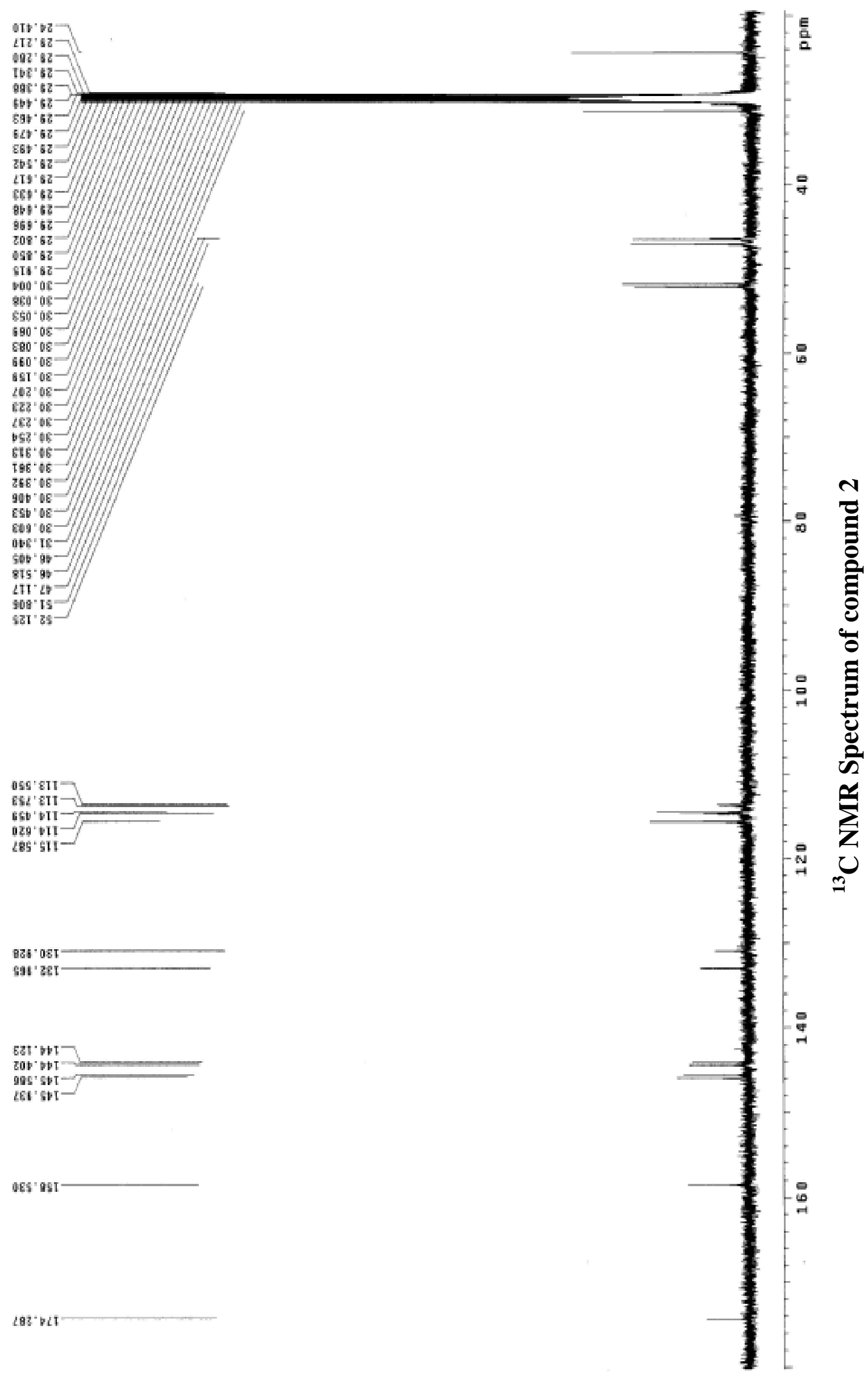



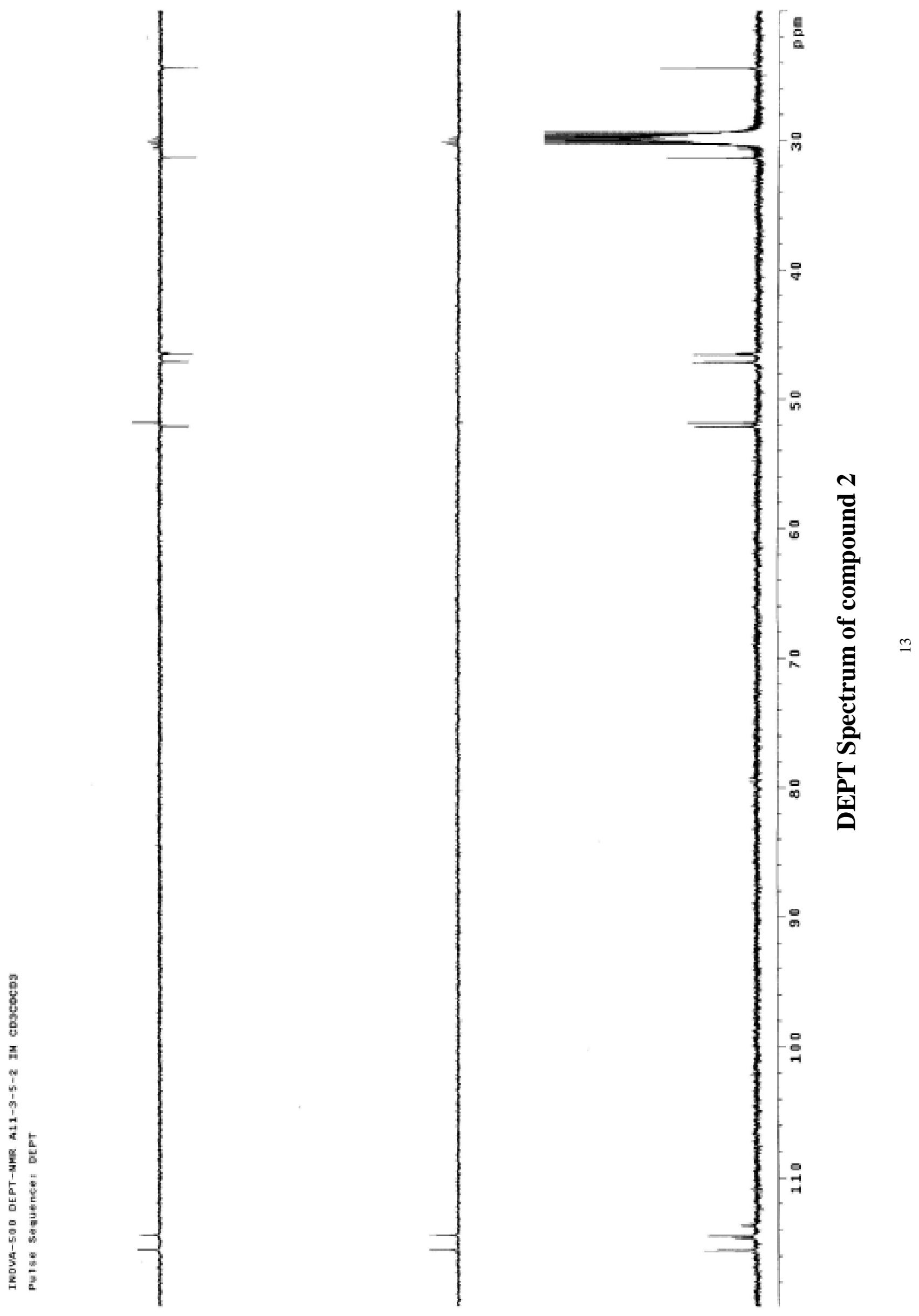

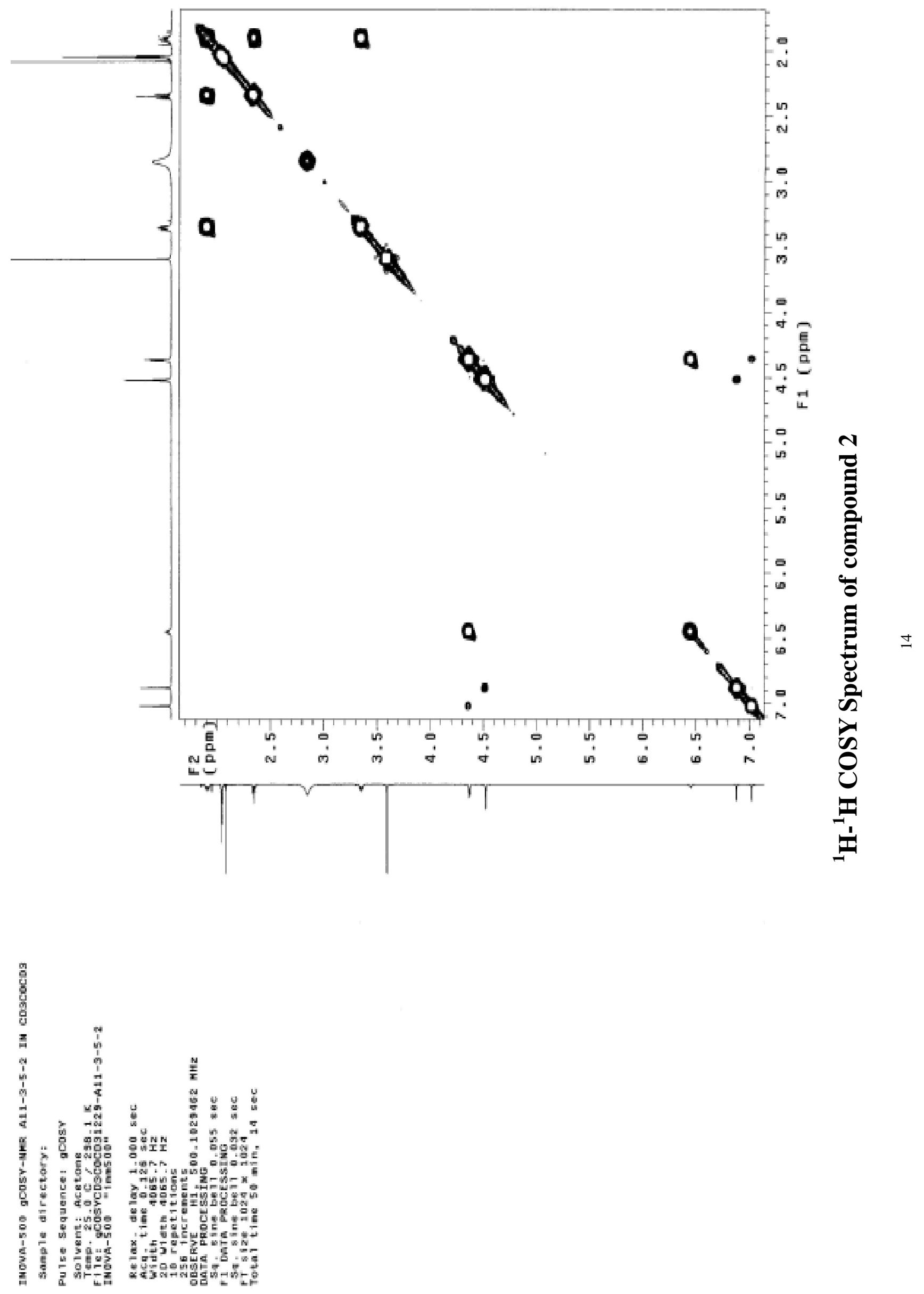
00

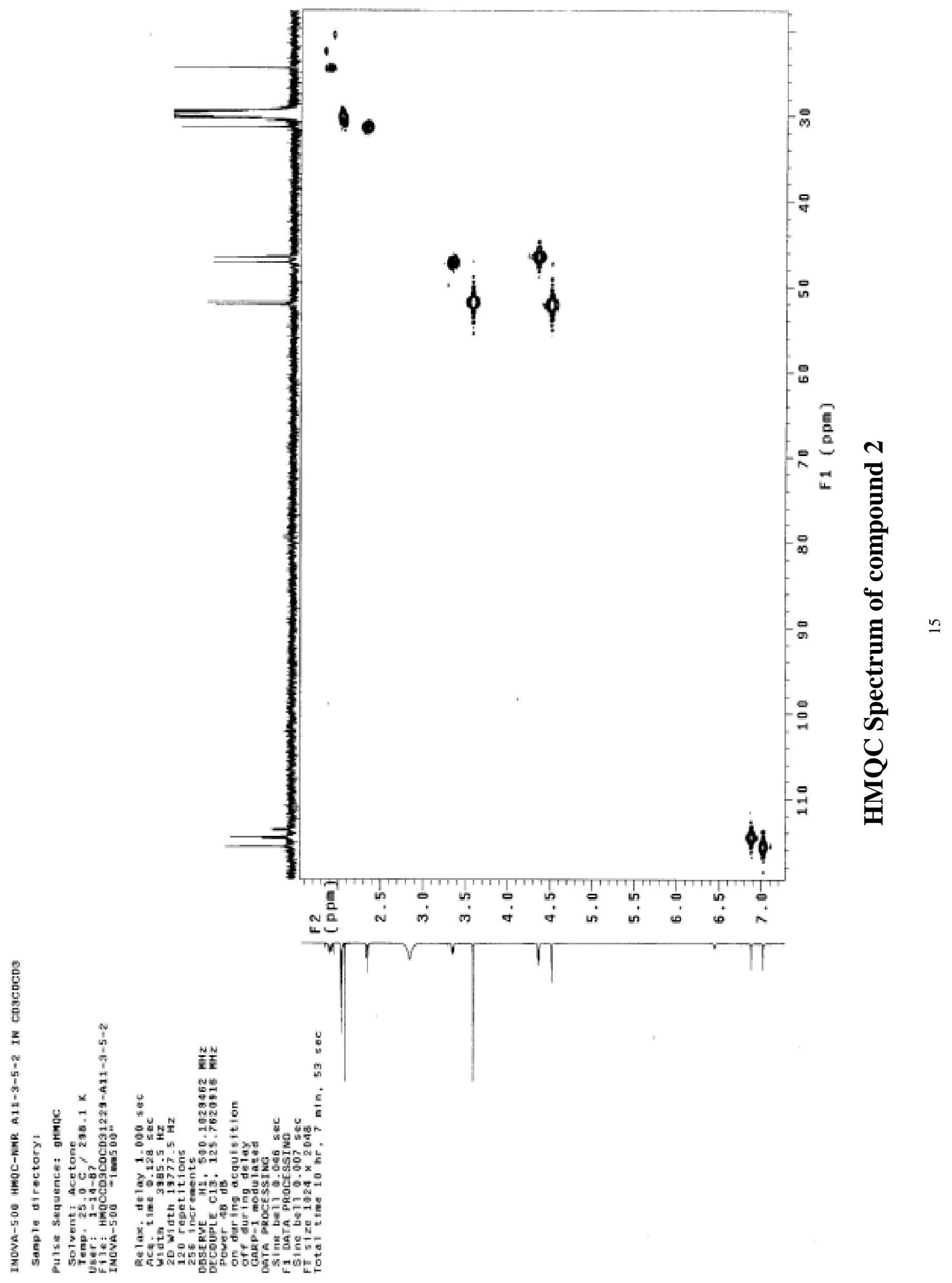




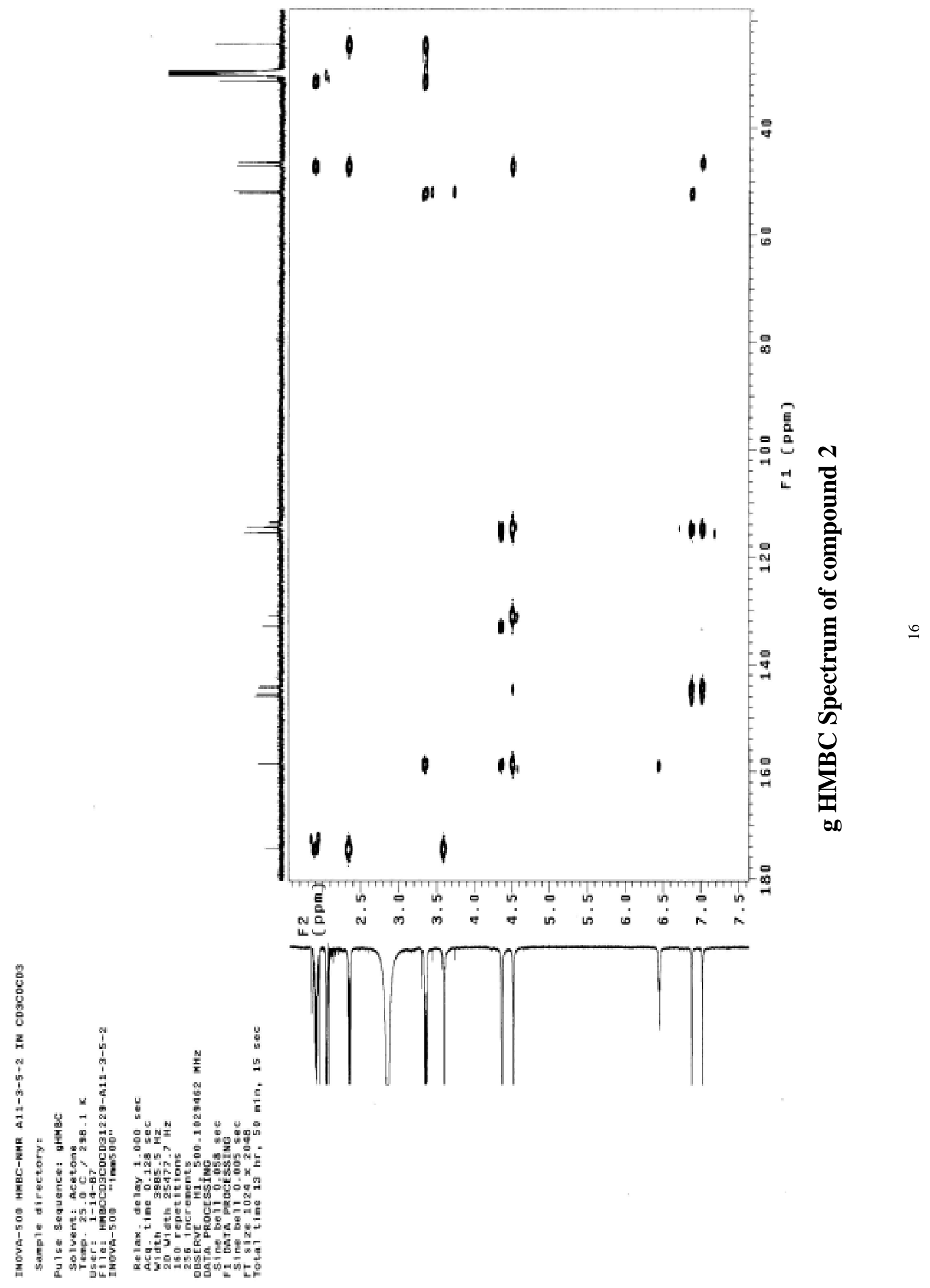




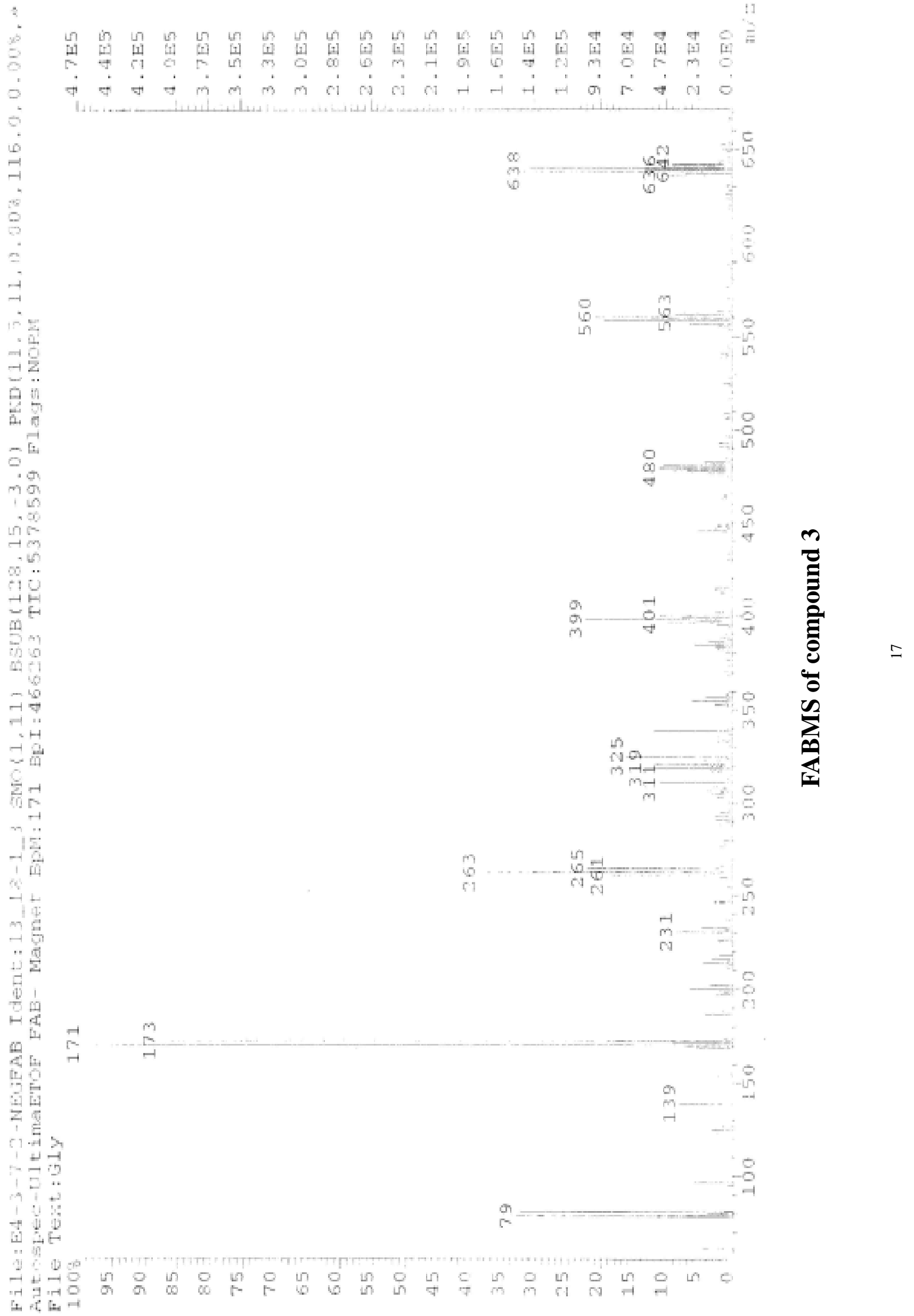




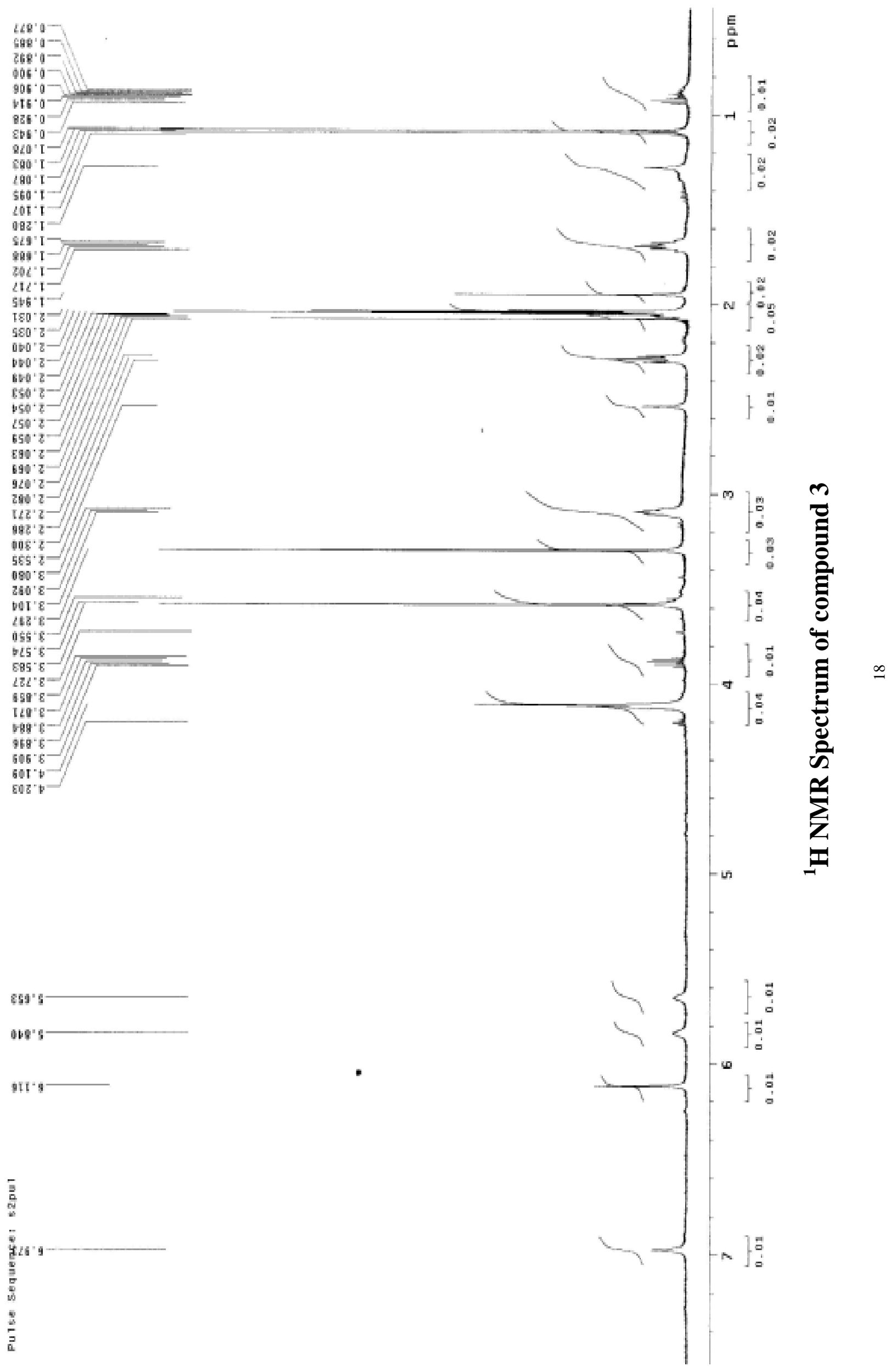




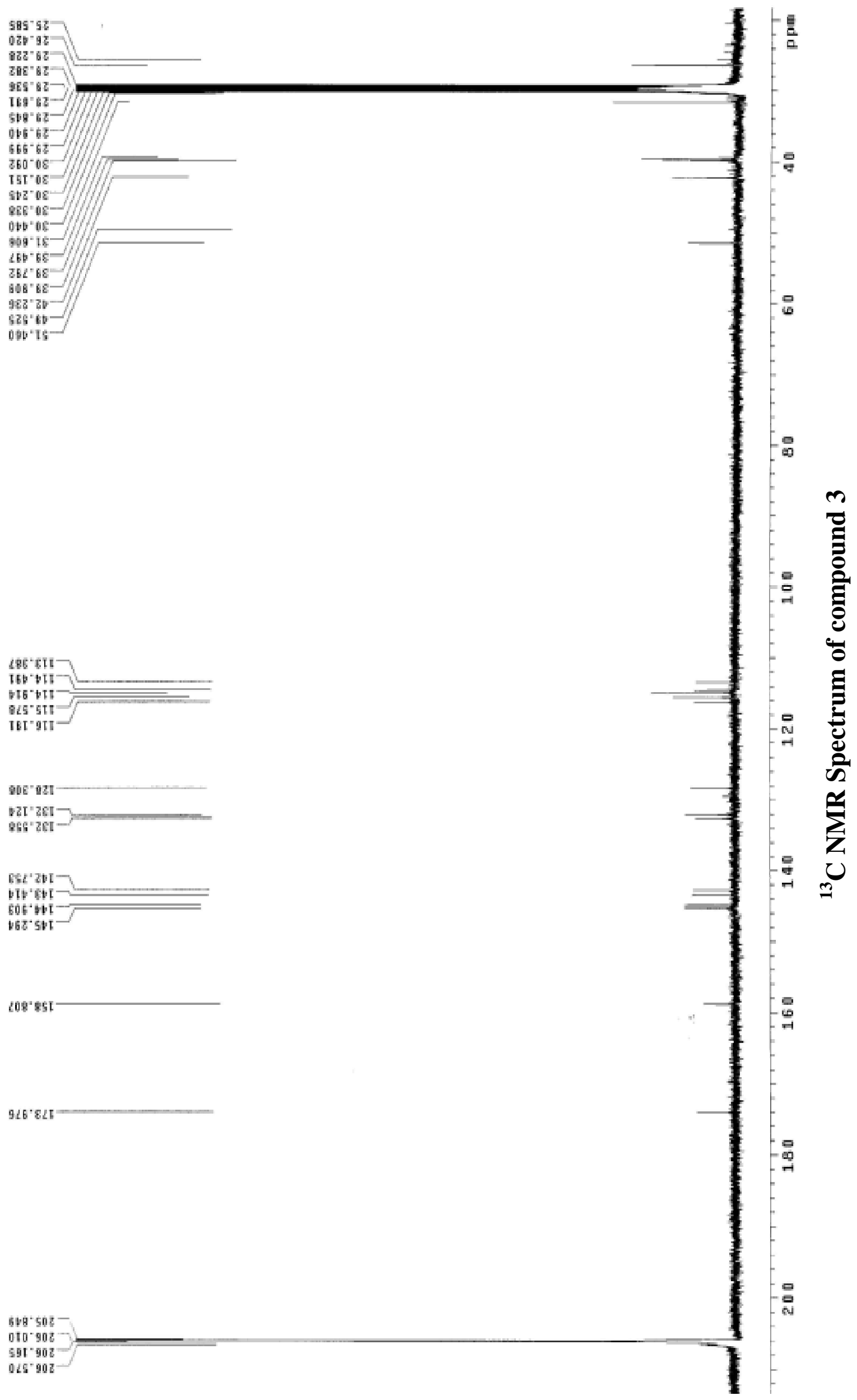



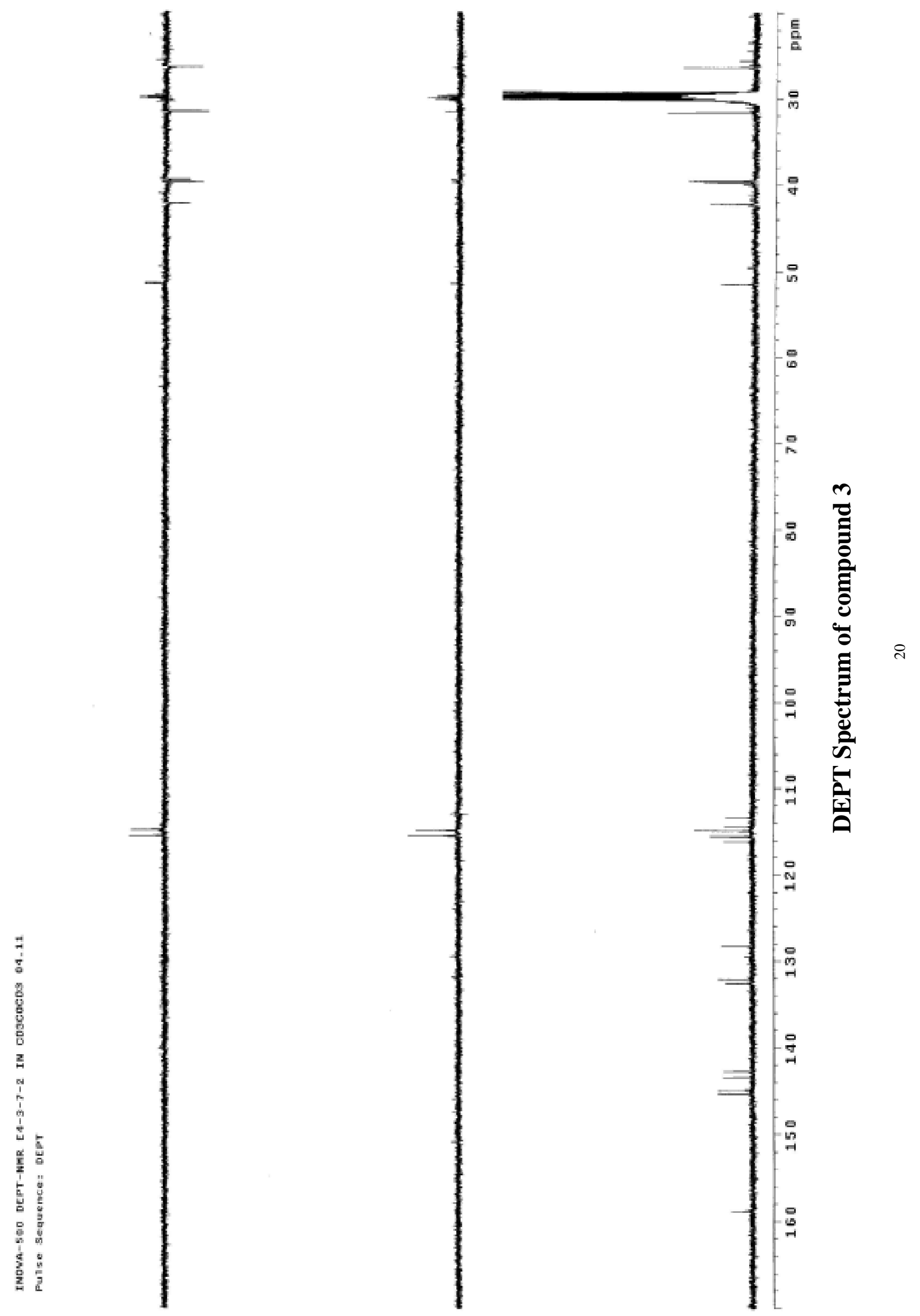

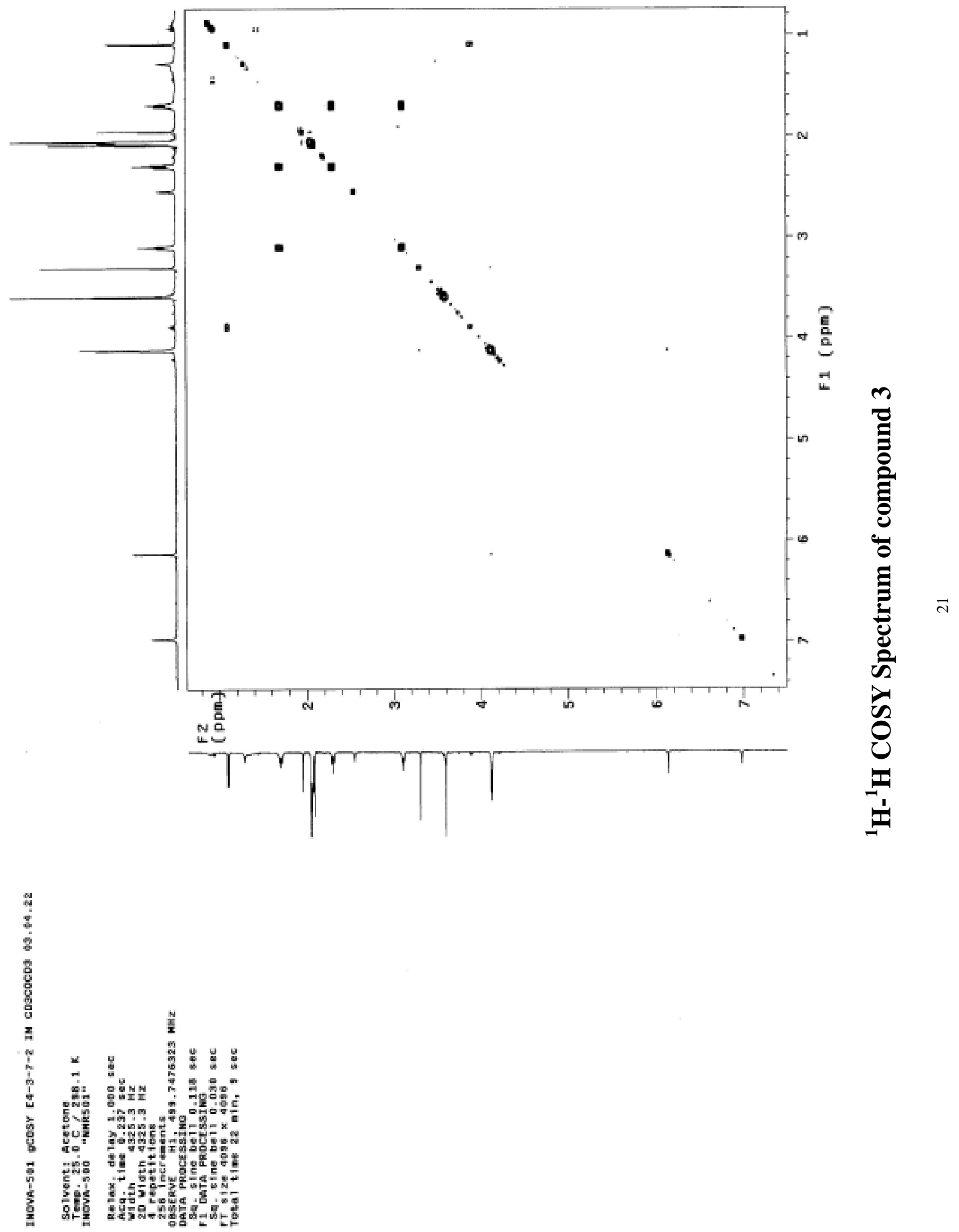


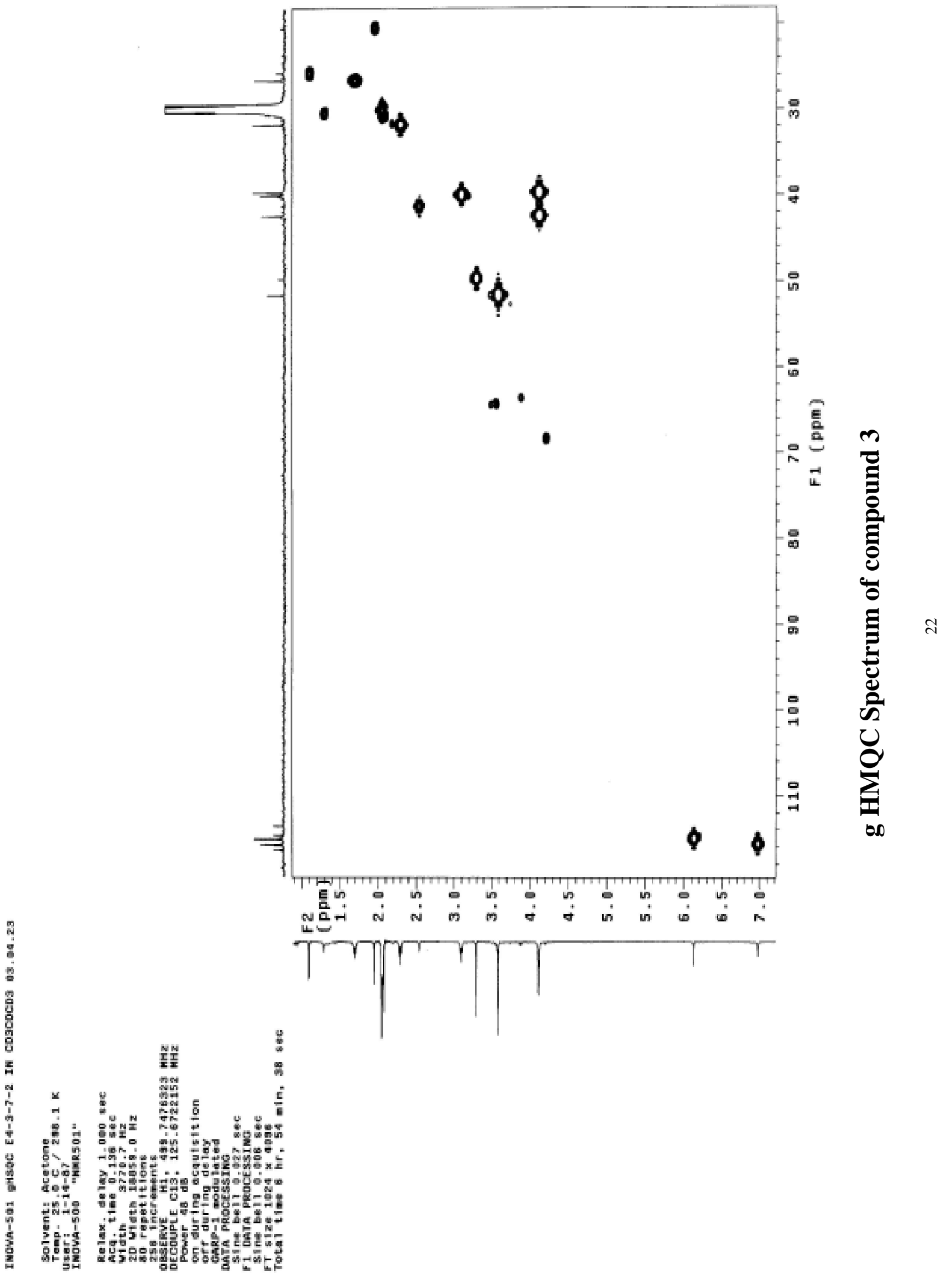




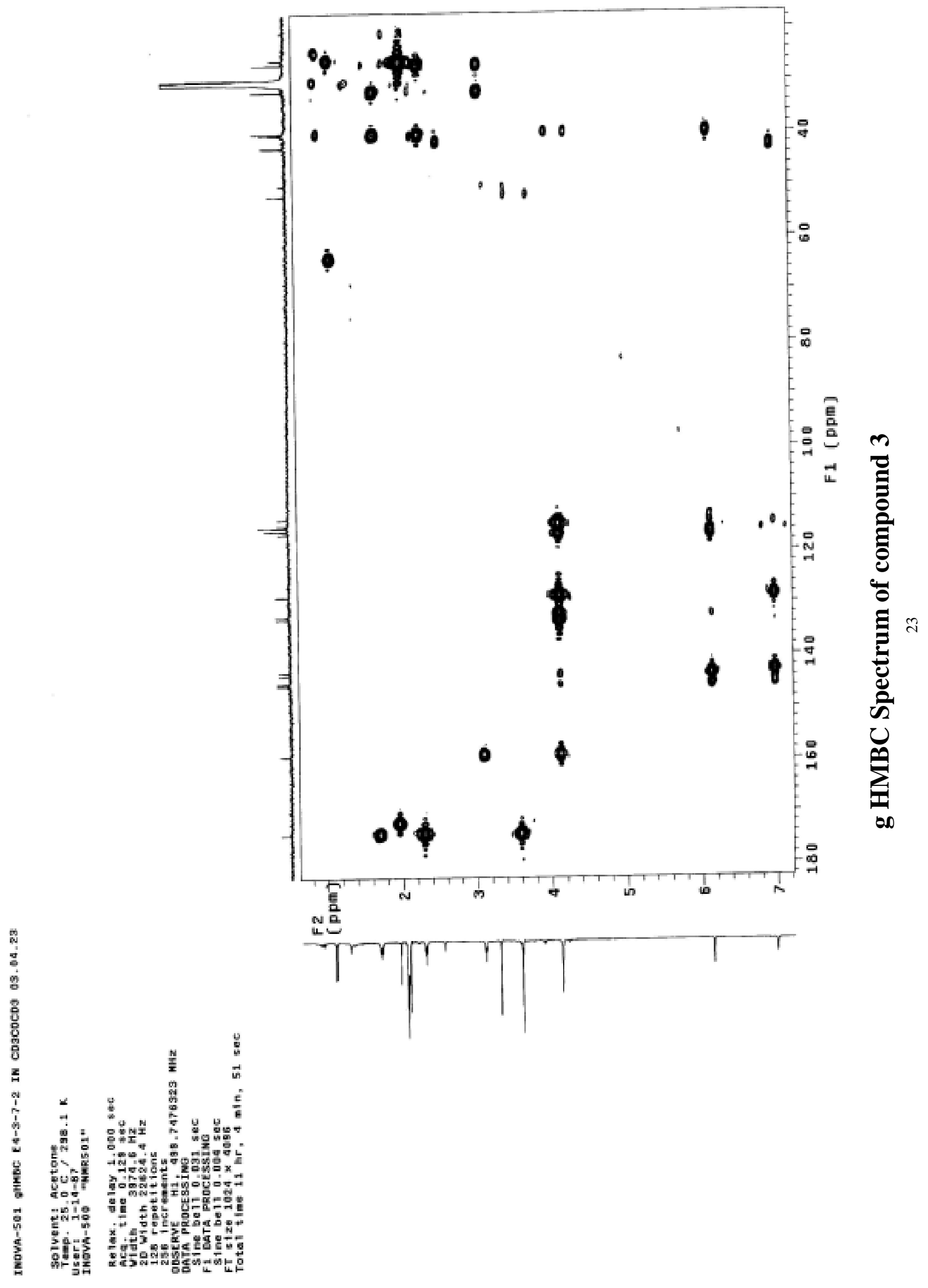




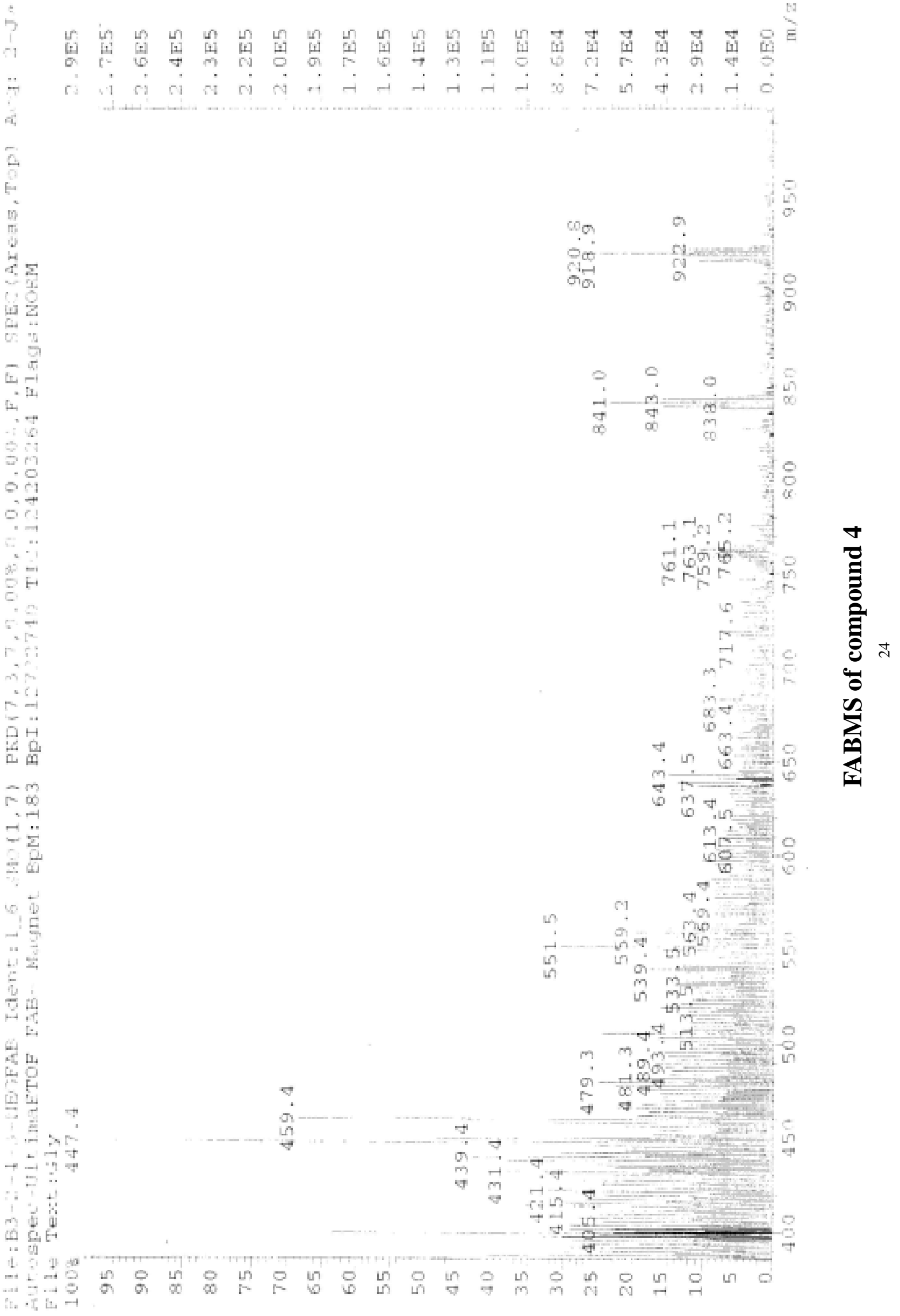




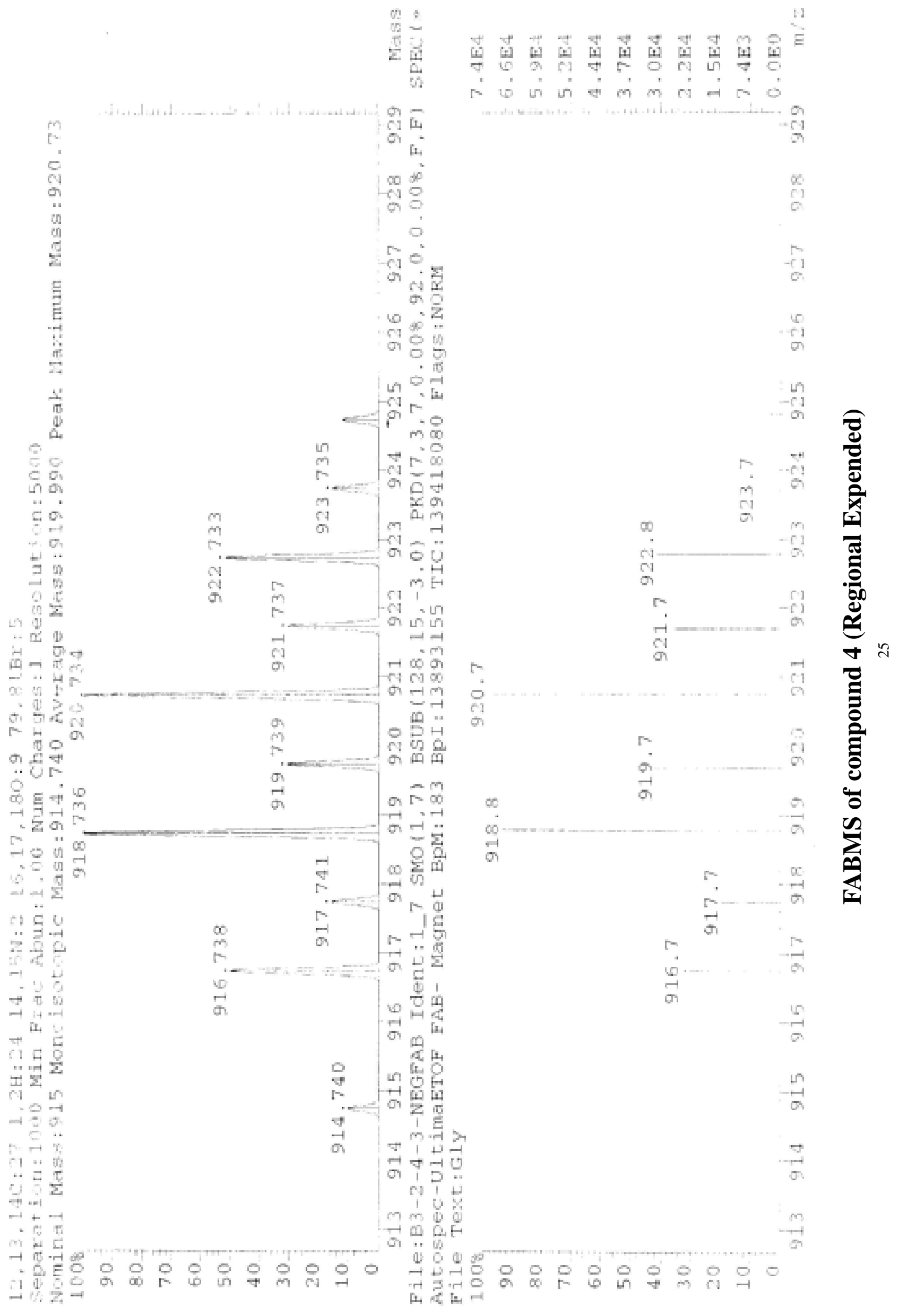




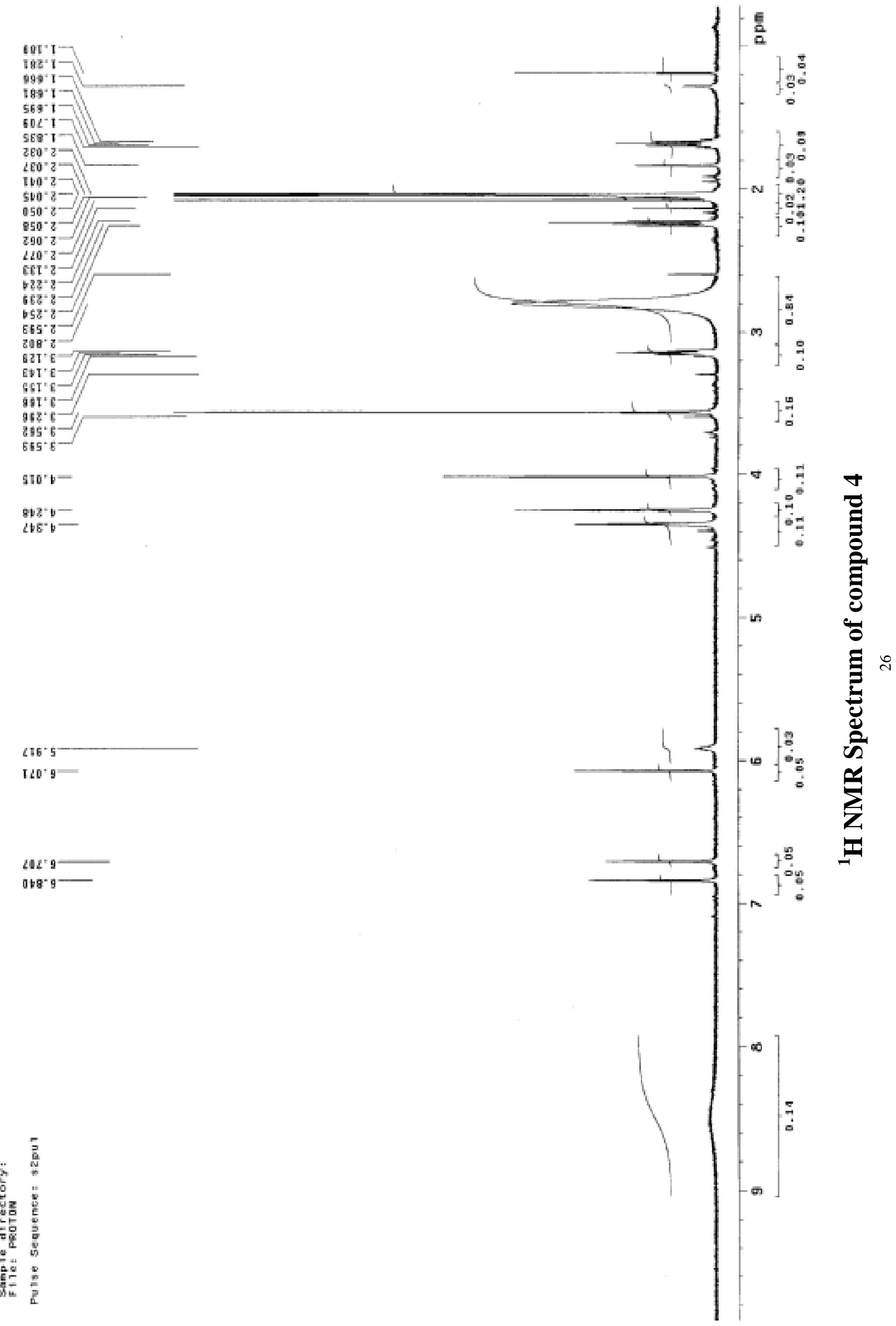




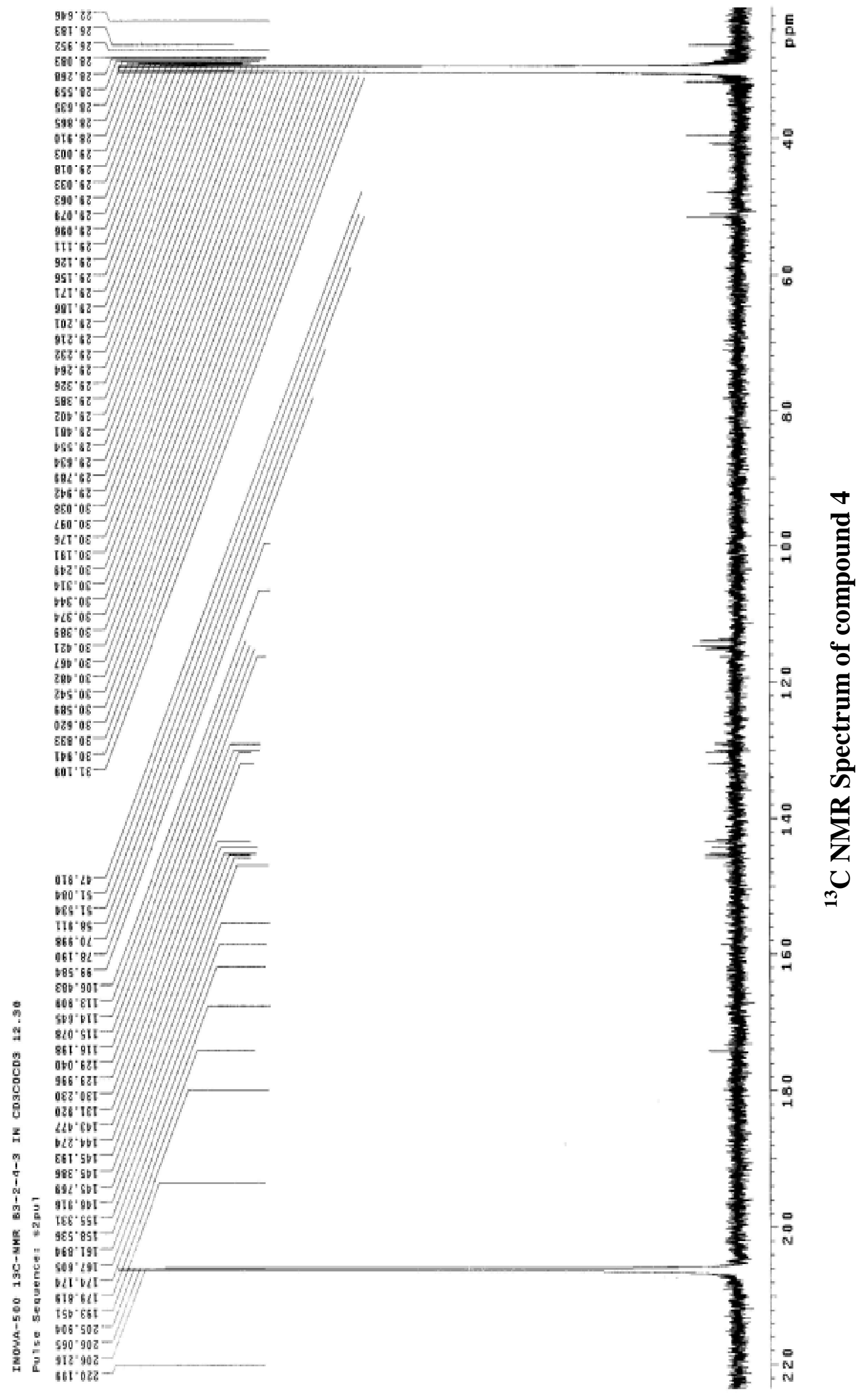



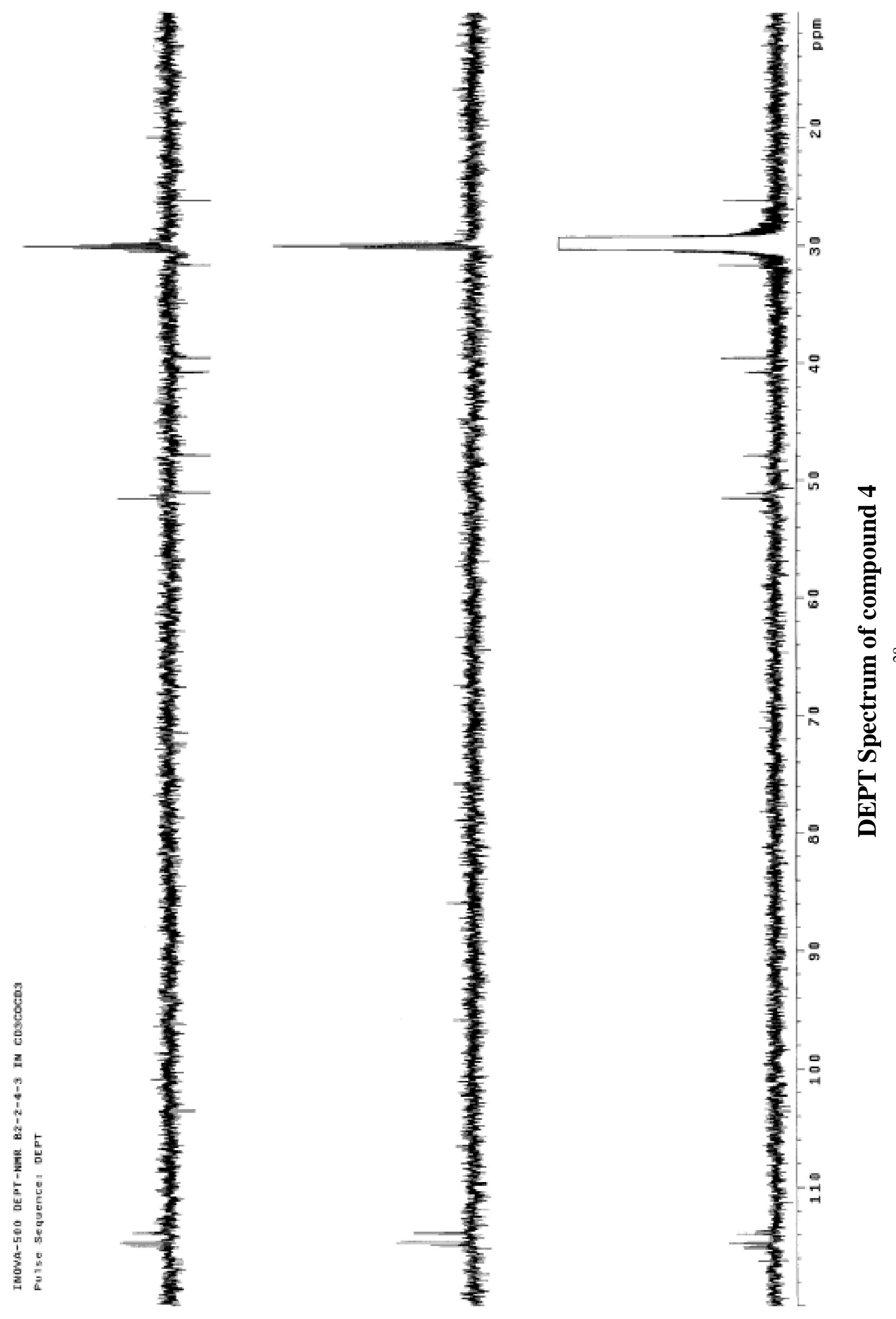

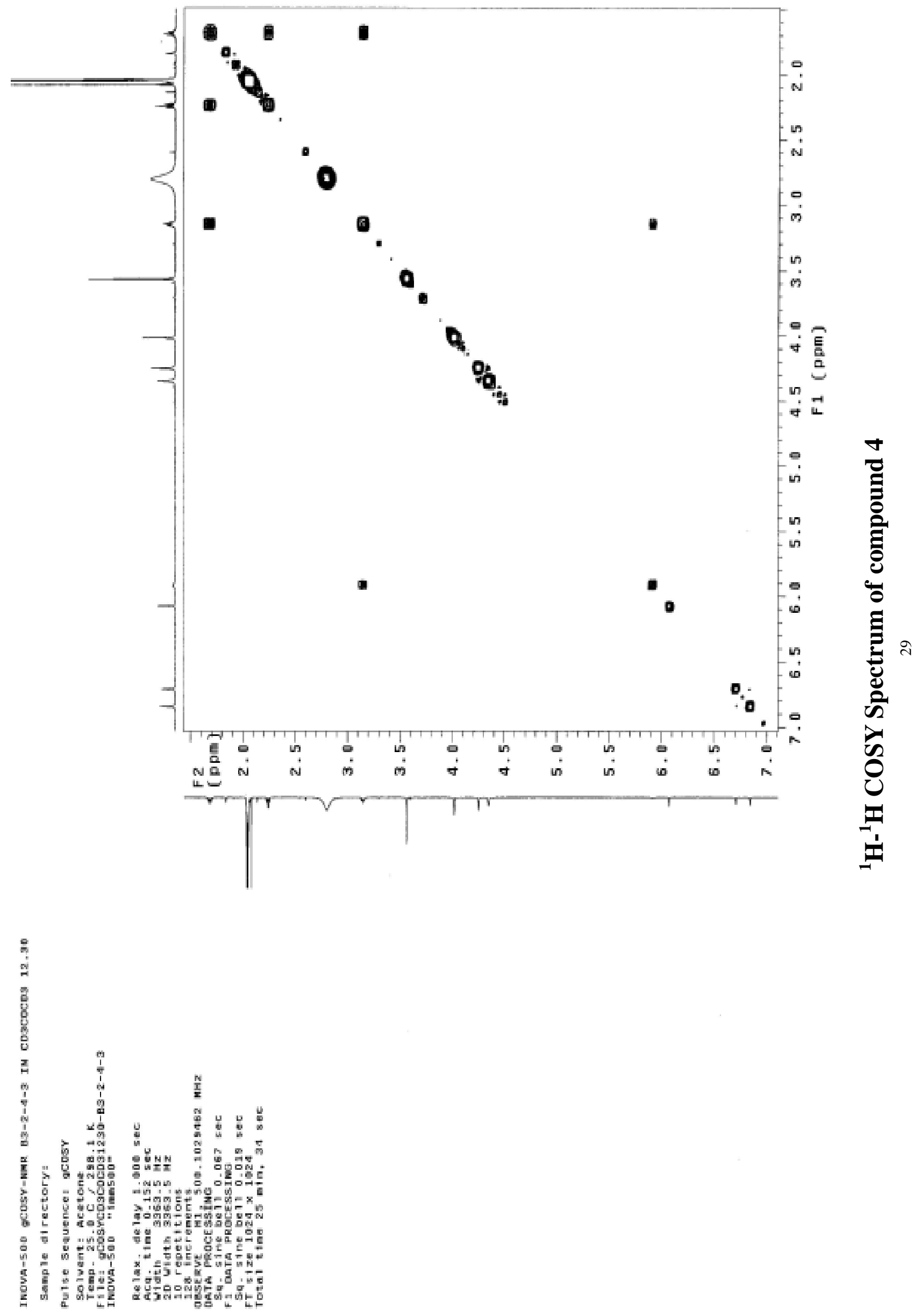


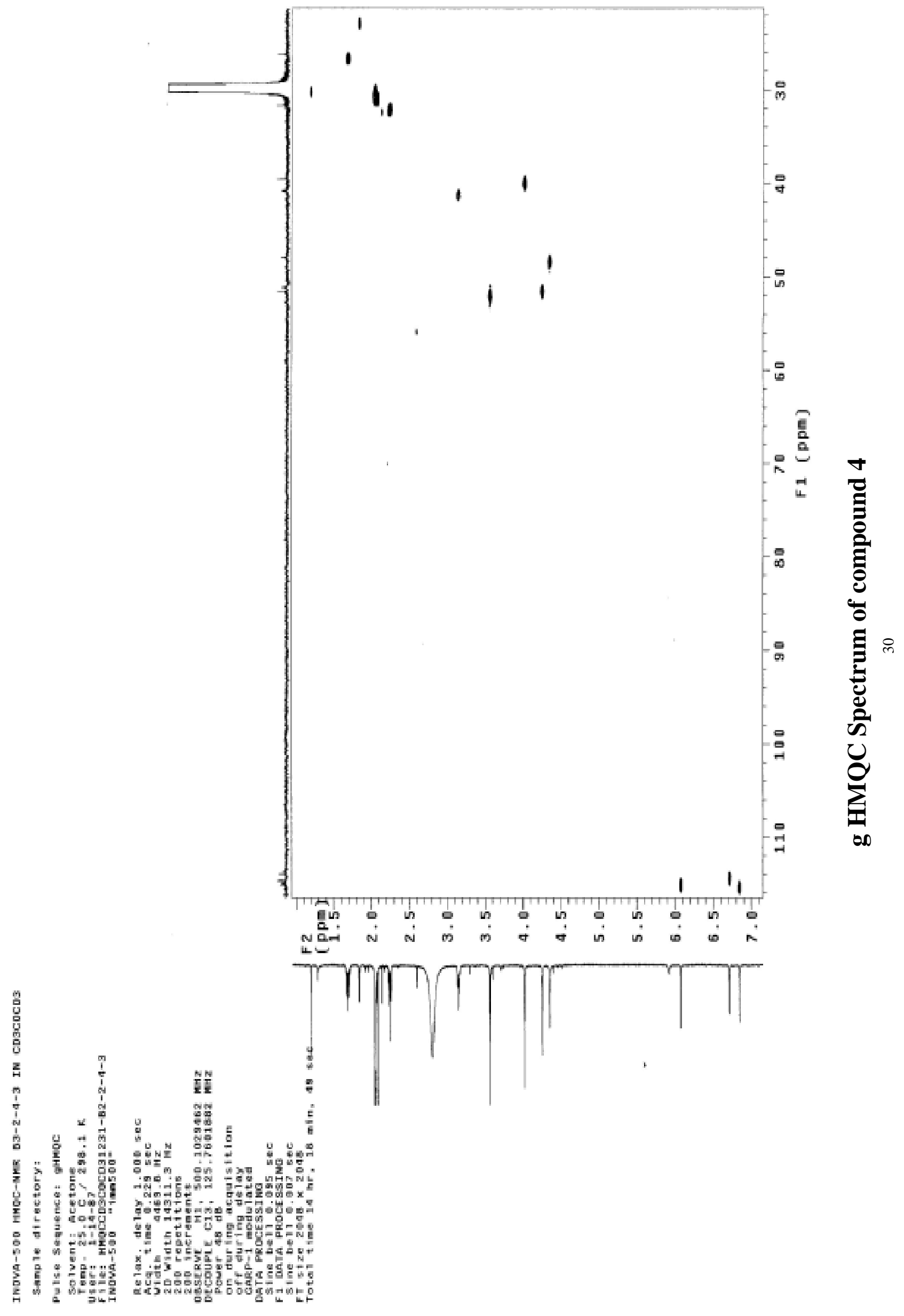




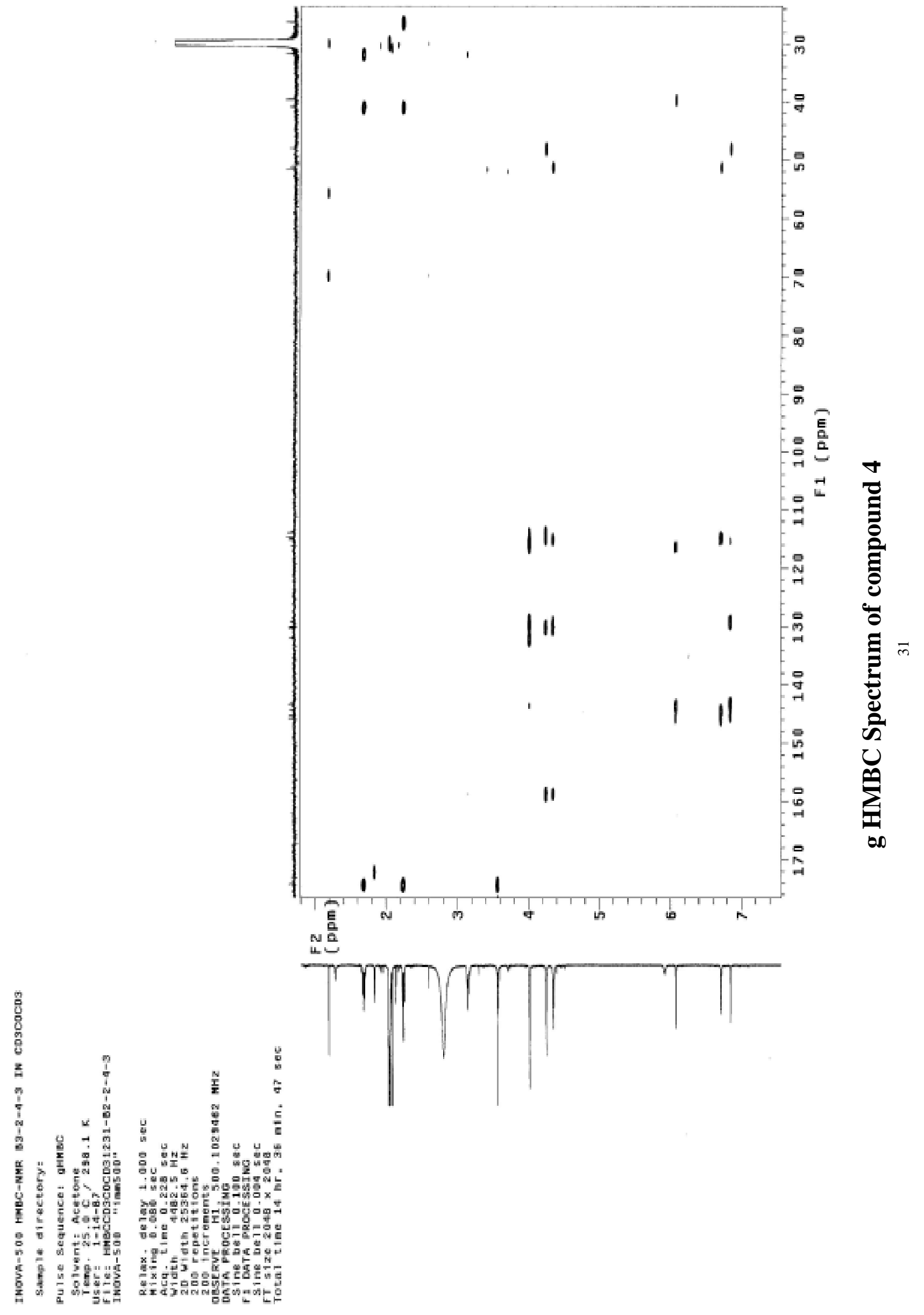




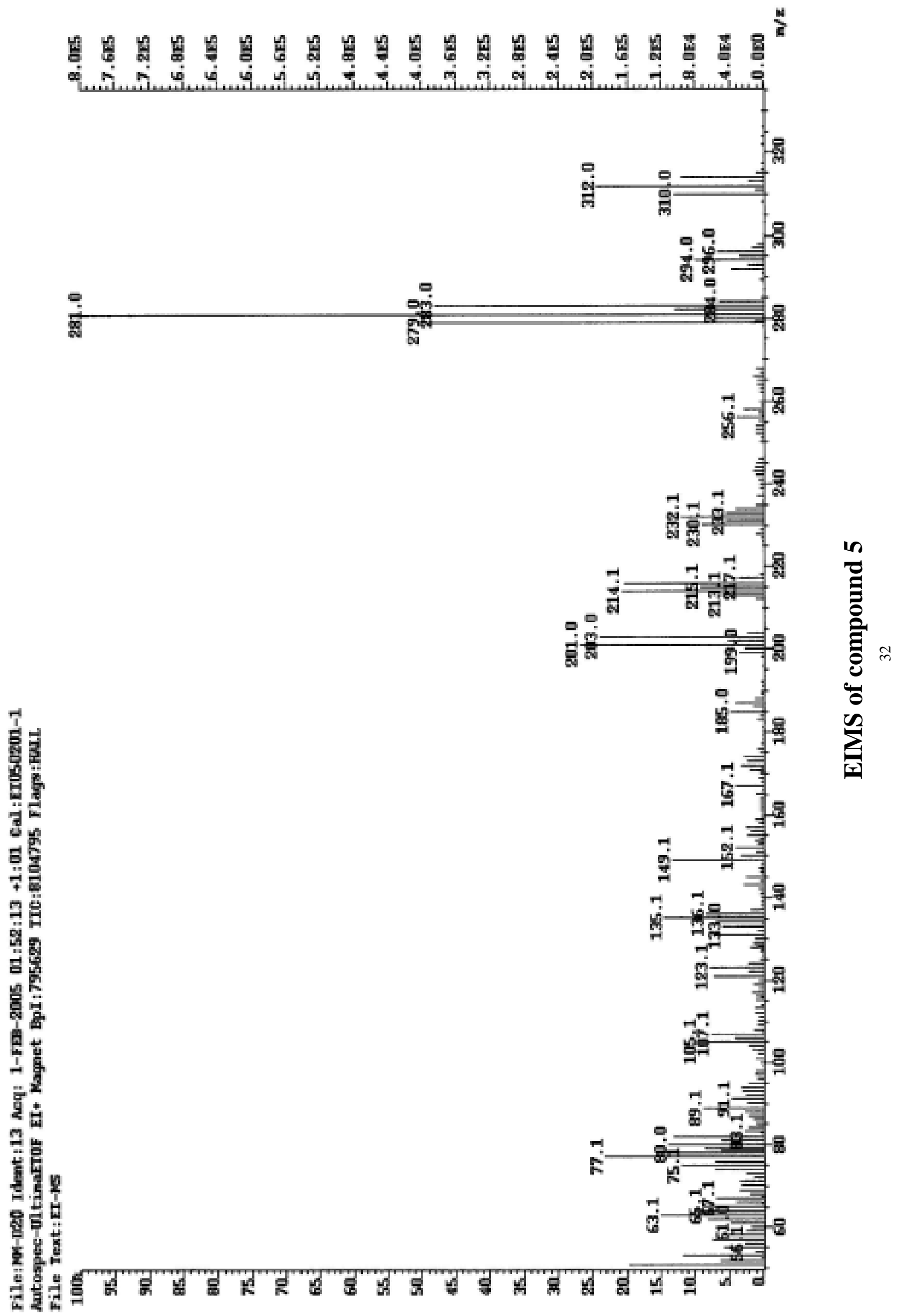




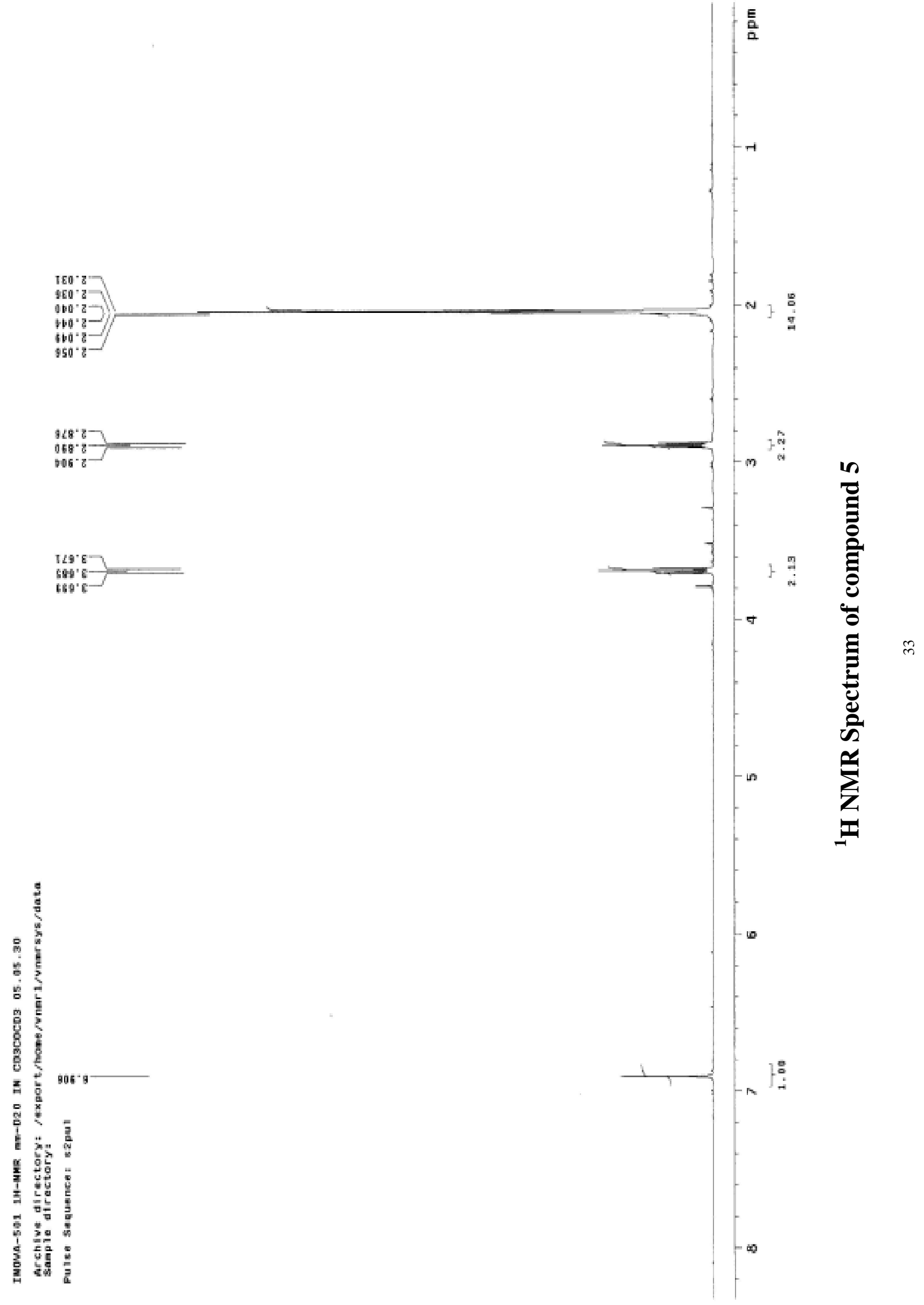




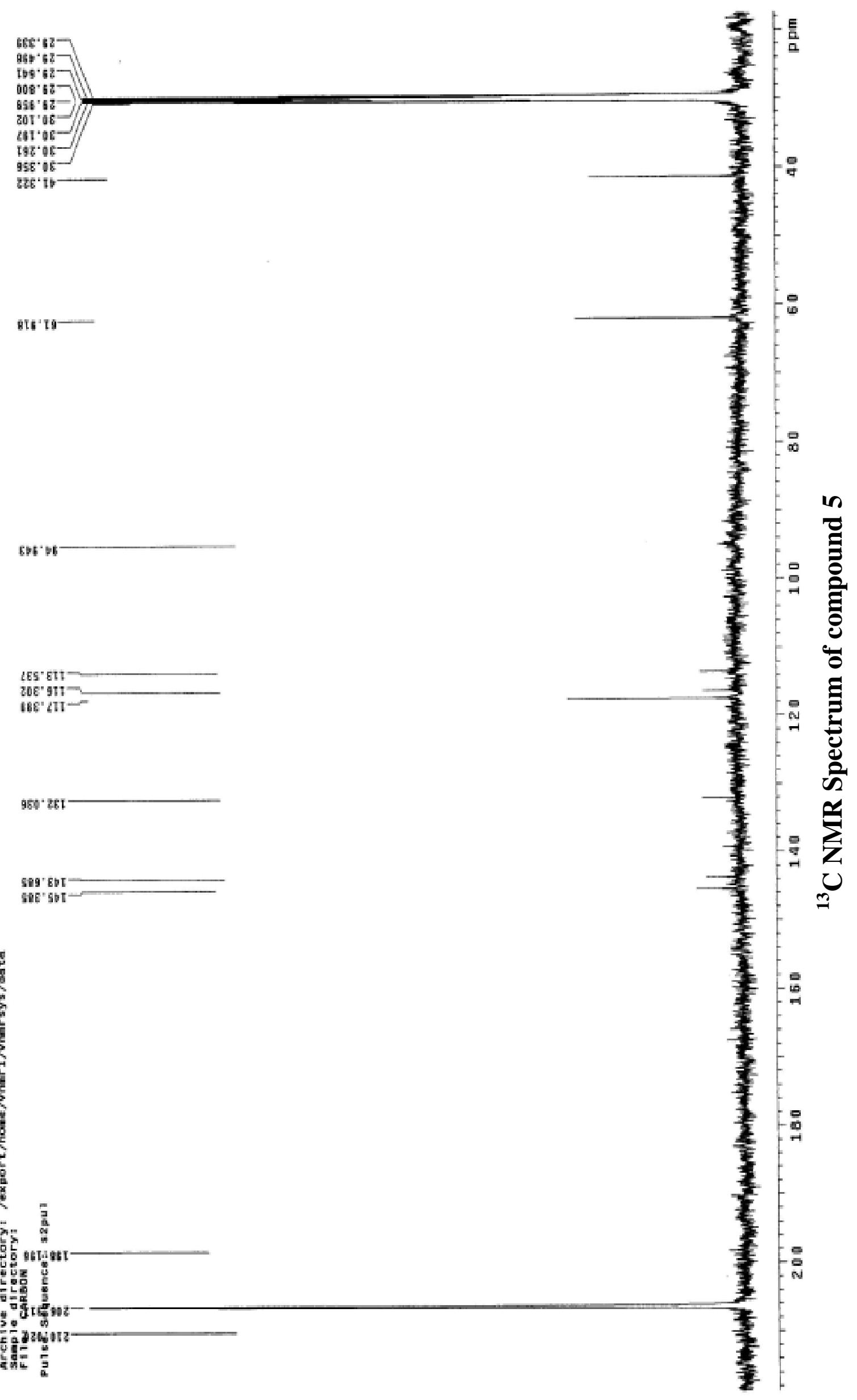




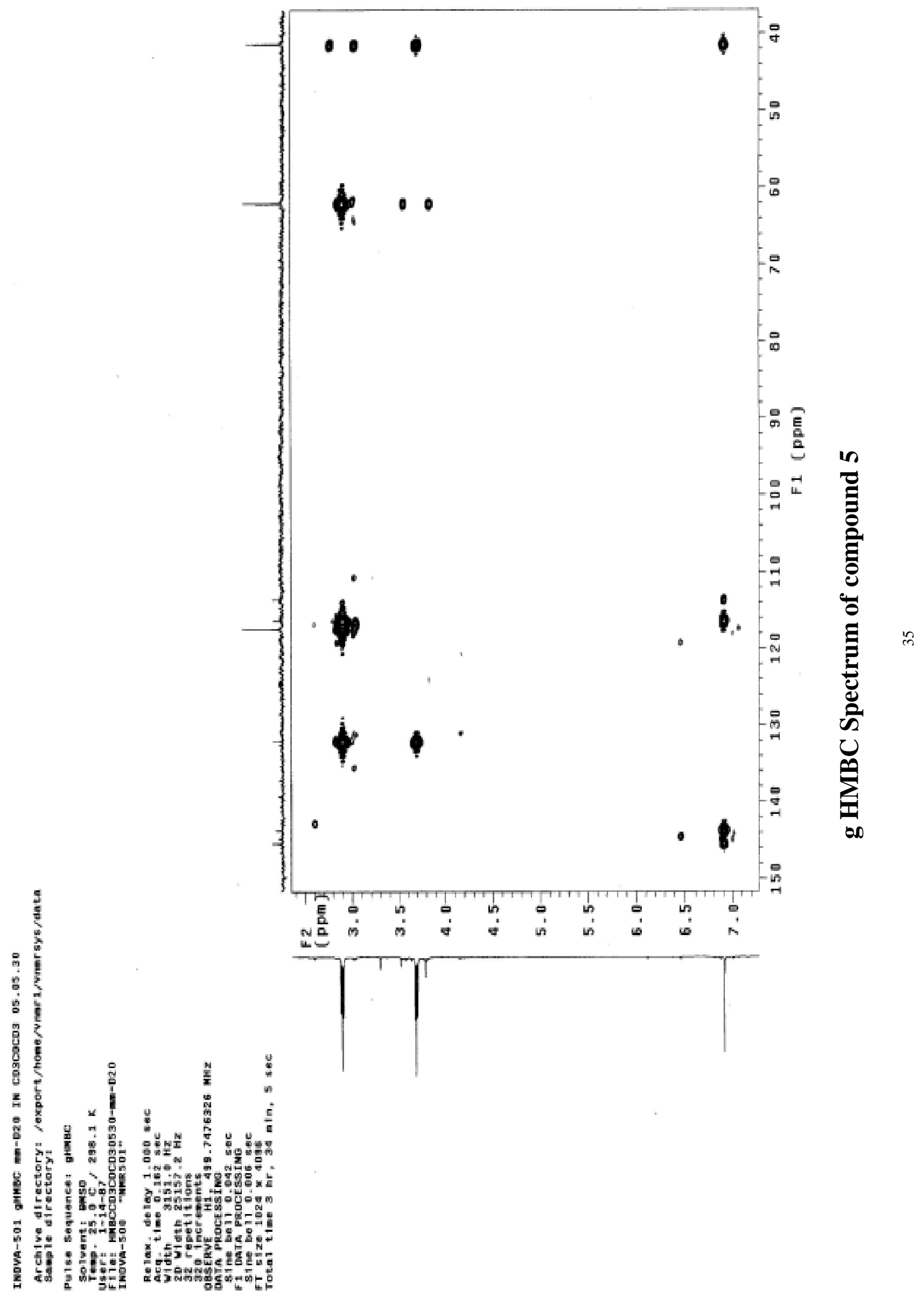




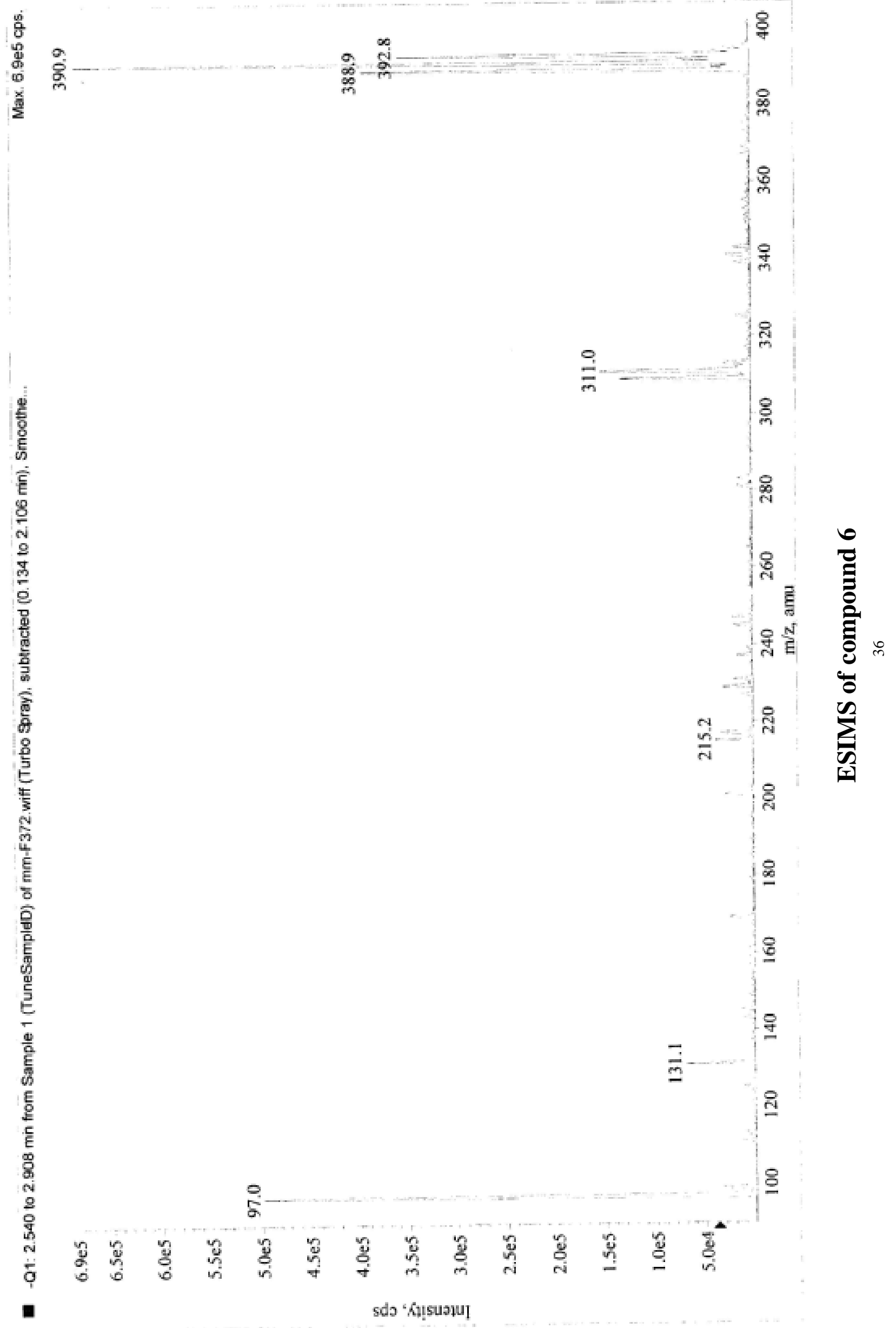




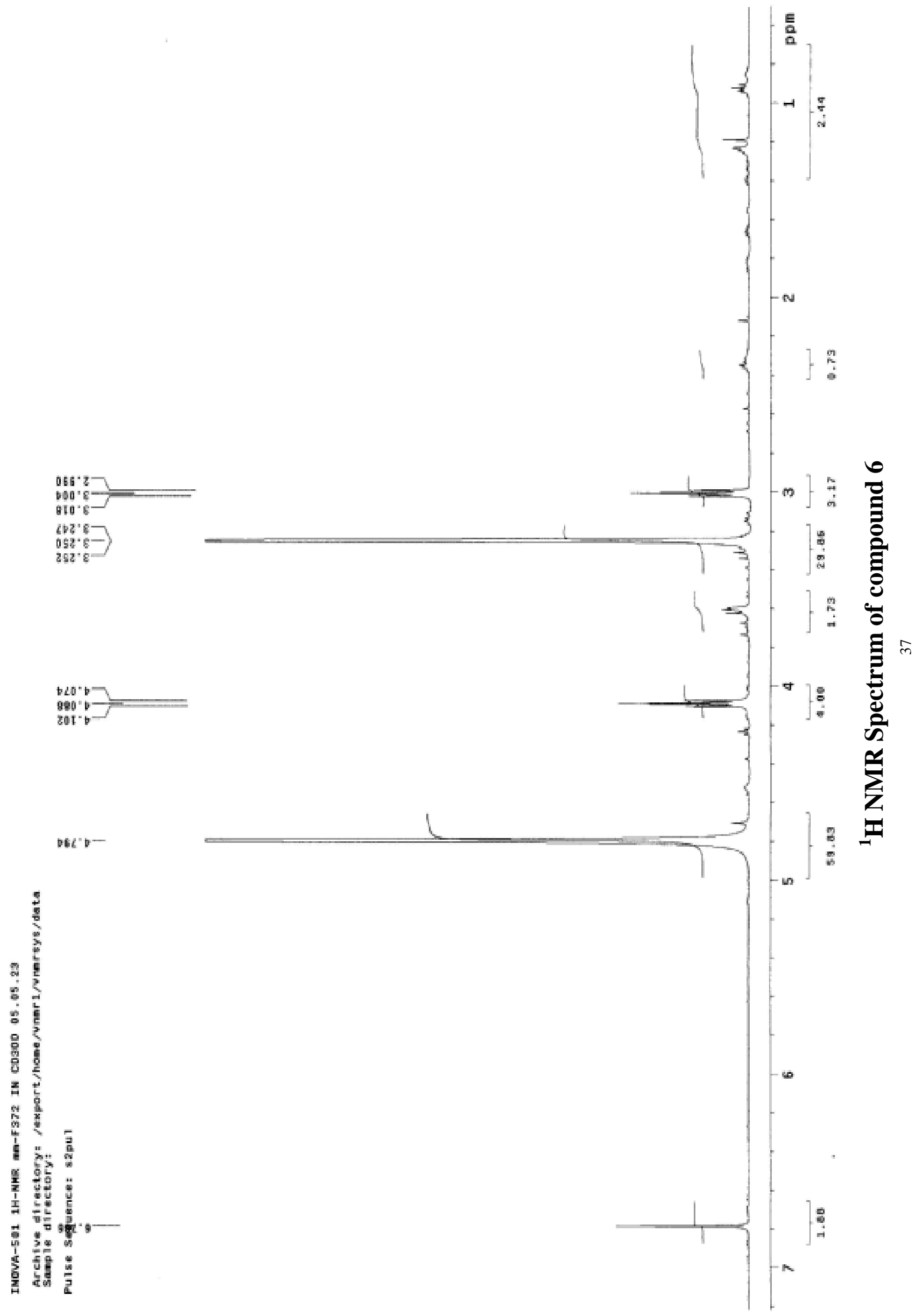




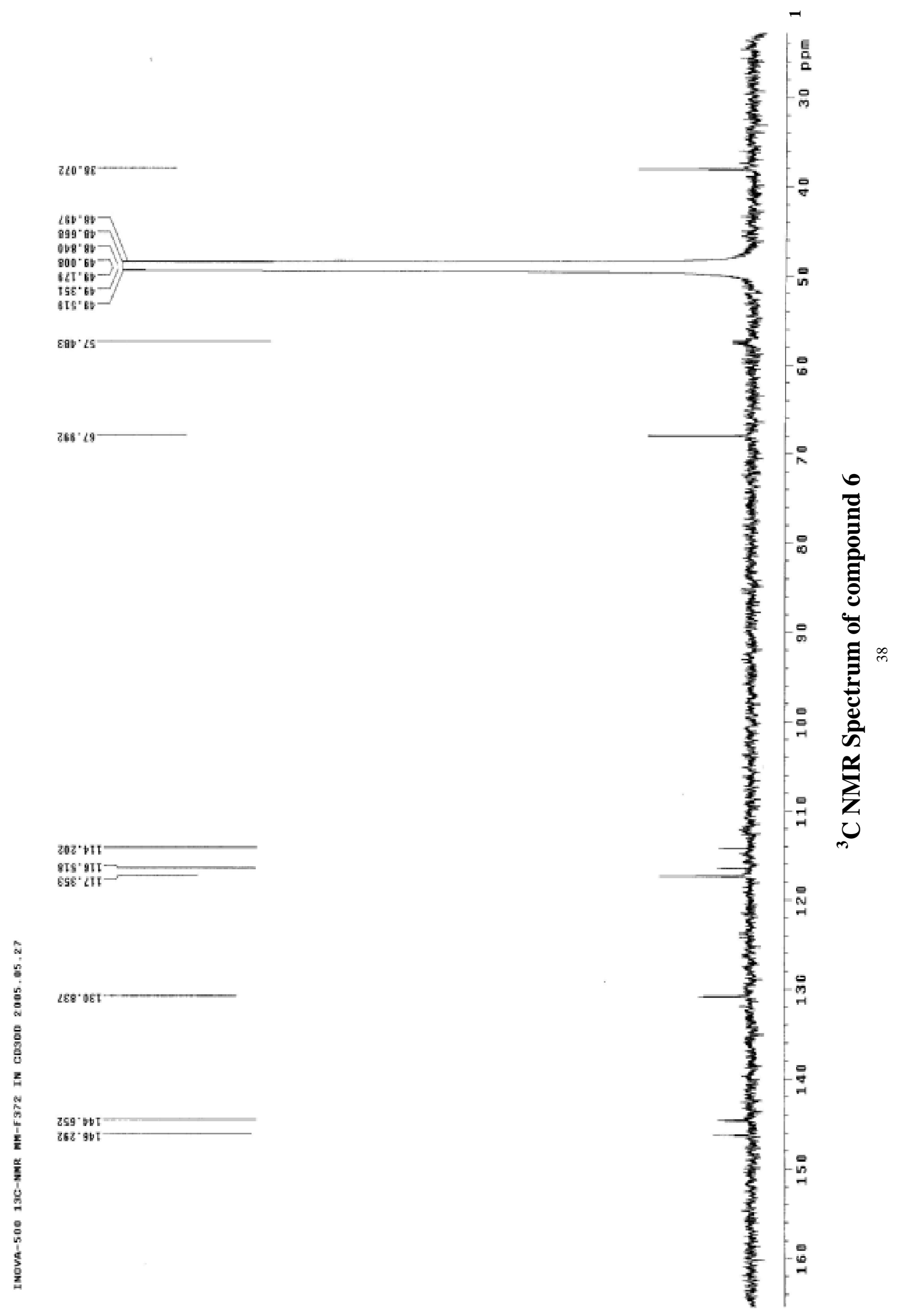




$$
11
$$




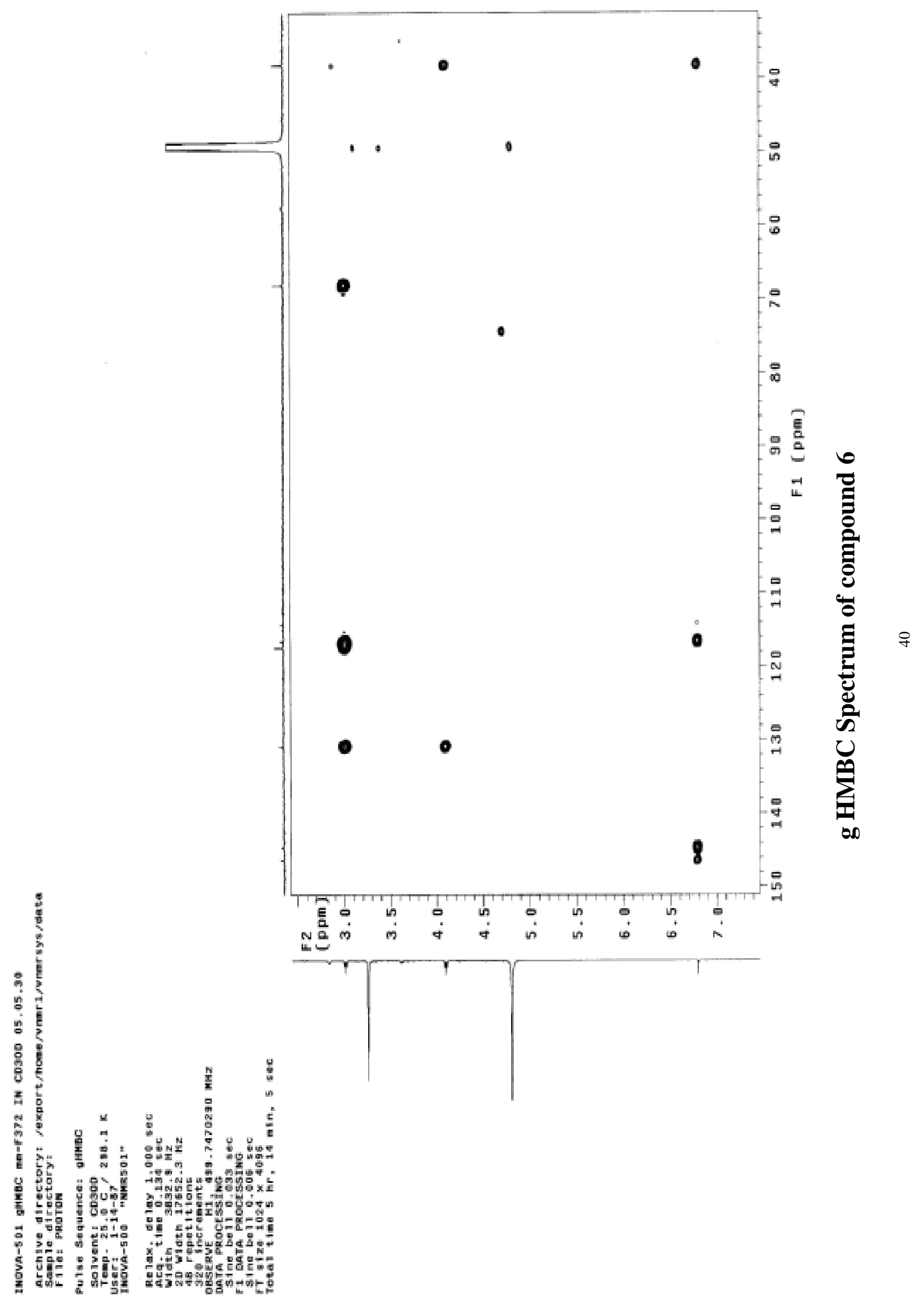




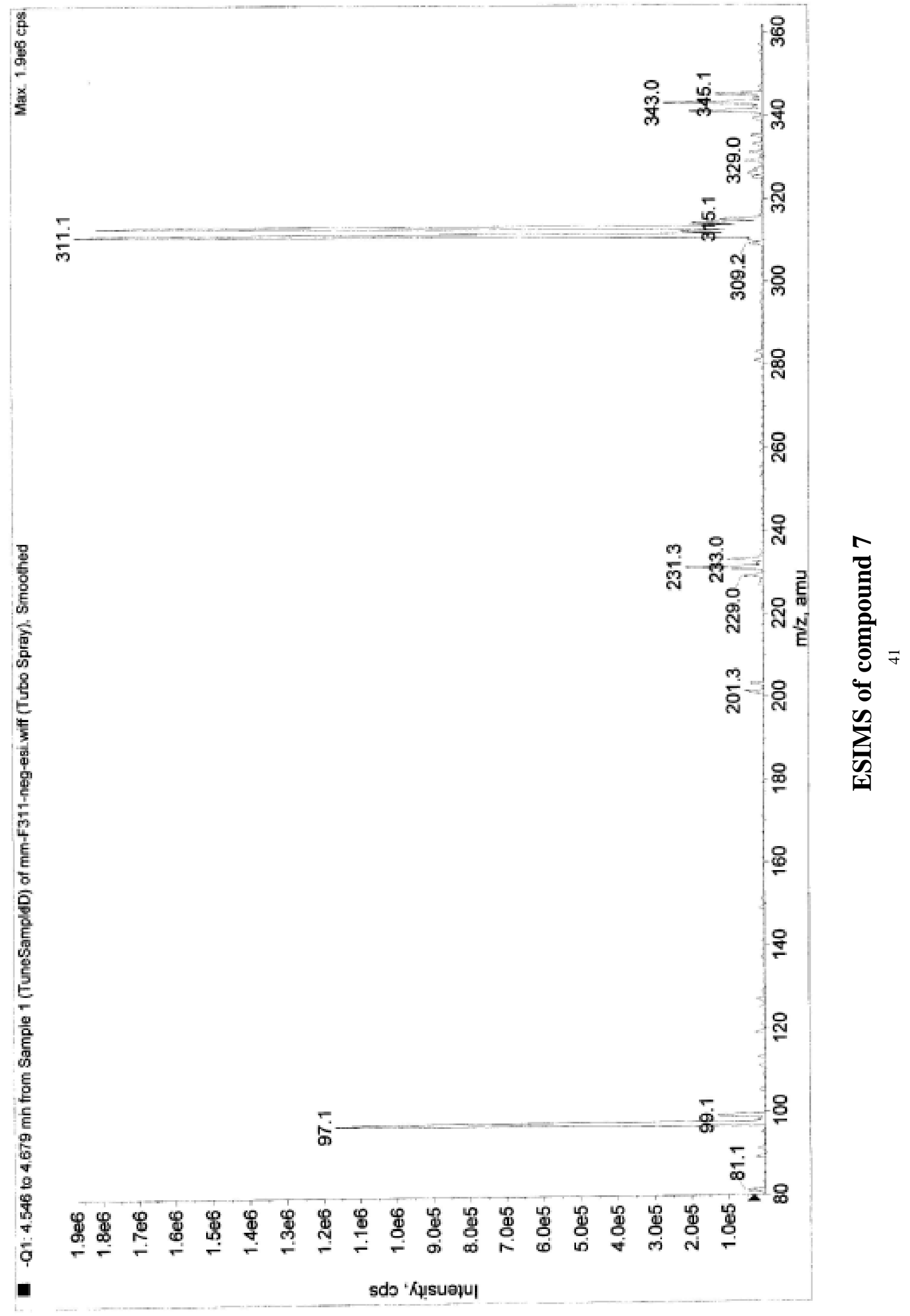




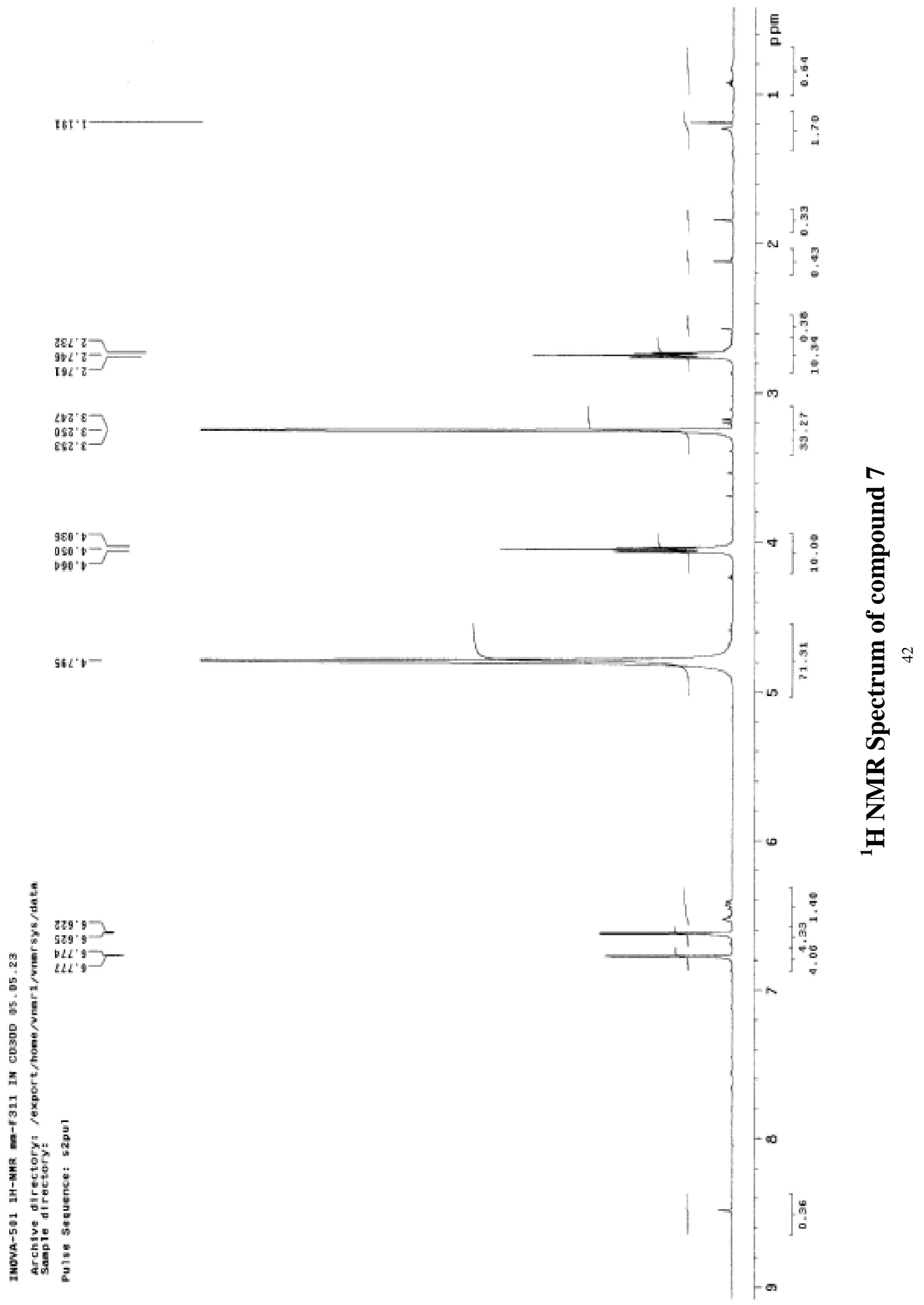




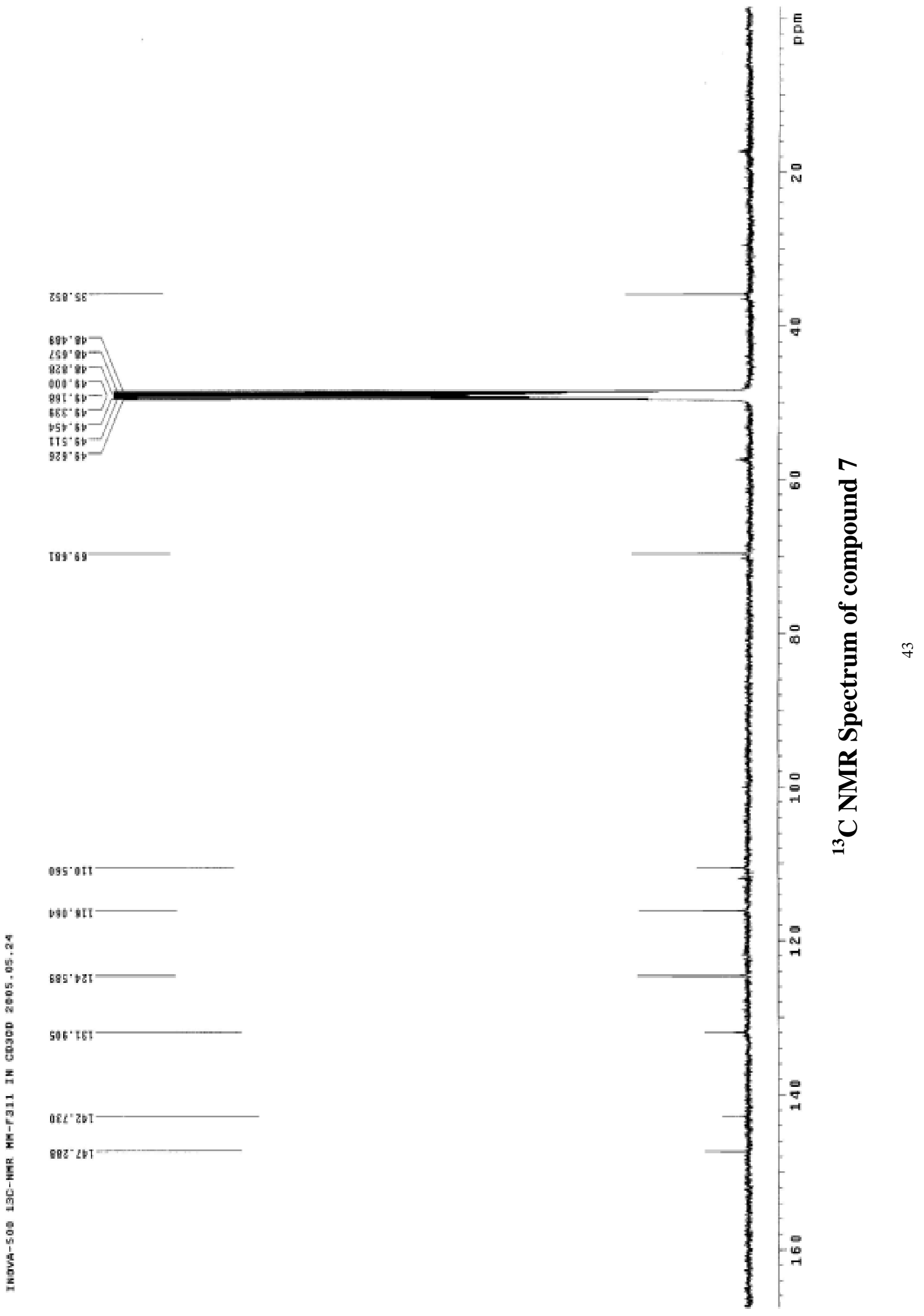



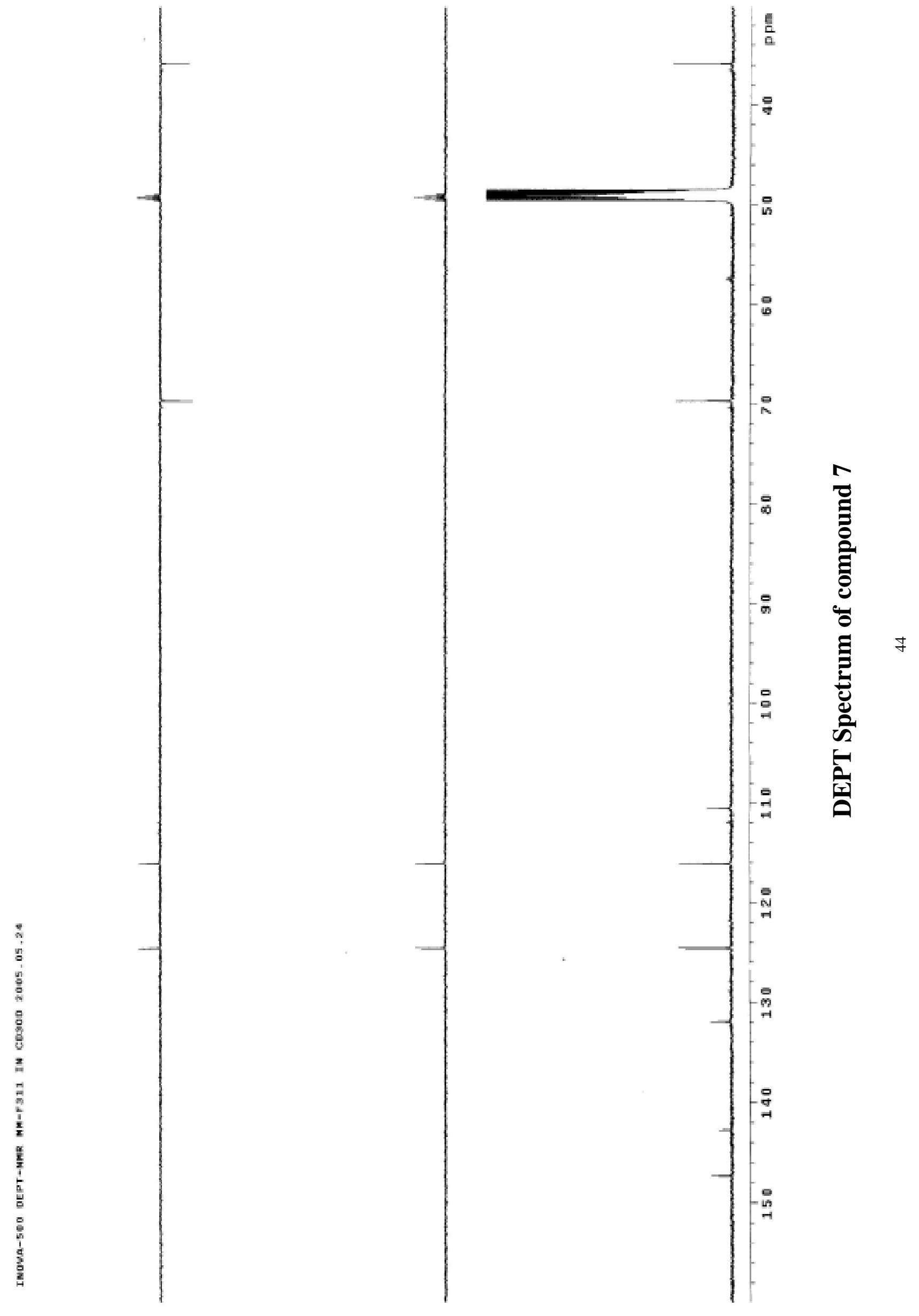


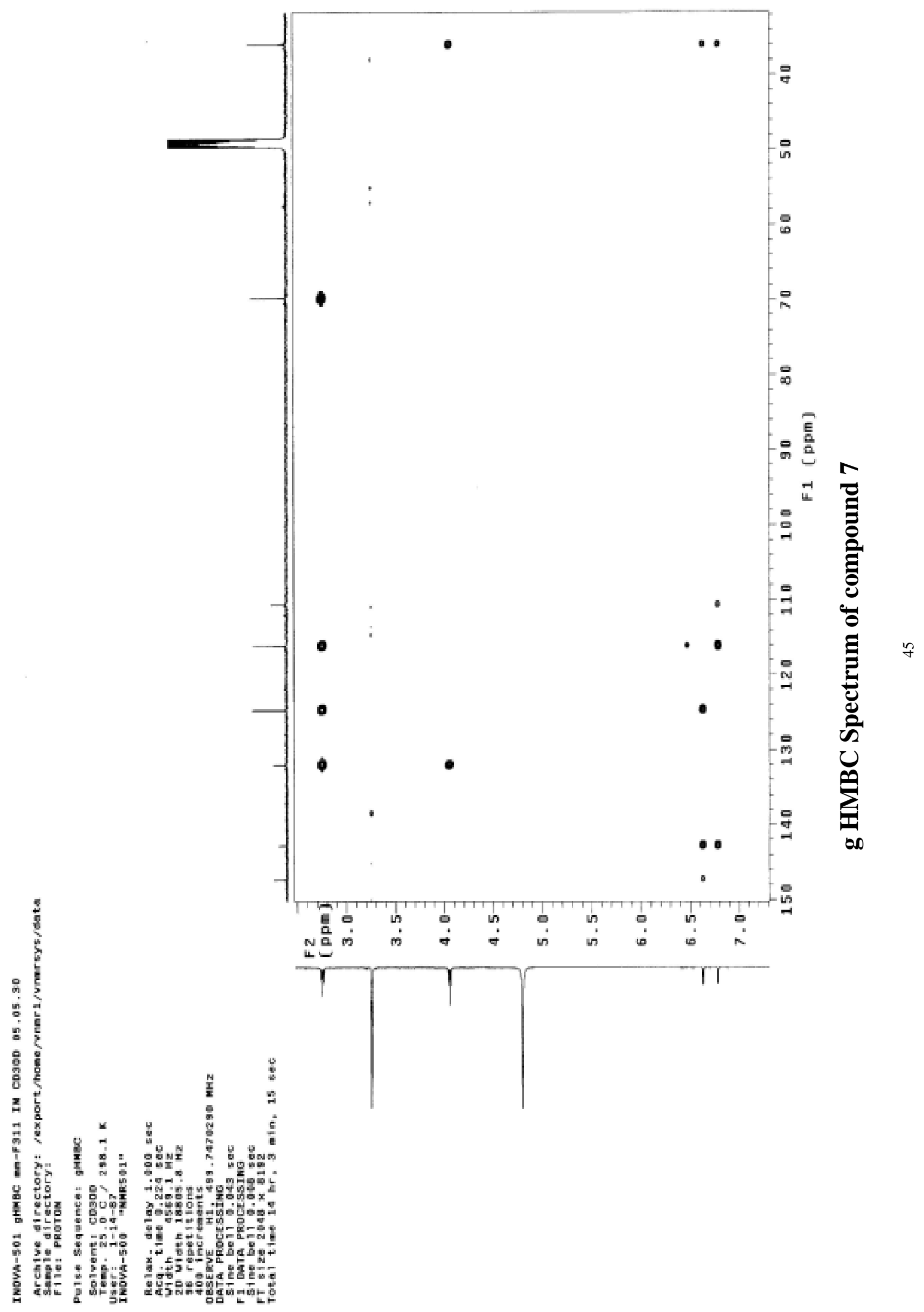


政
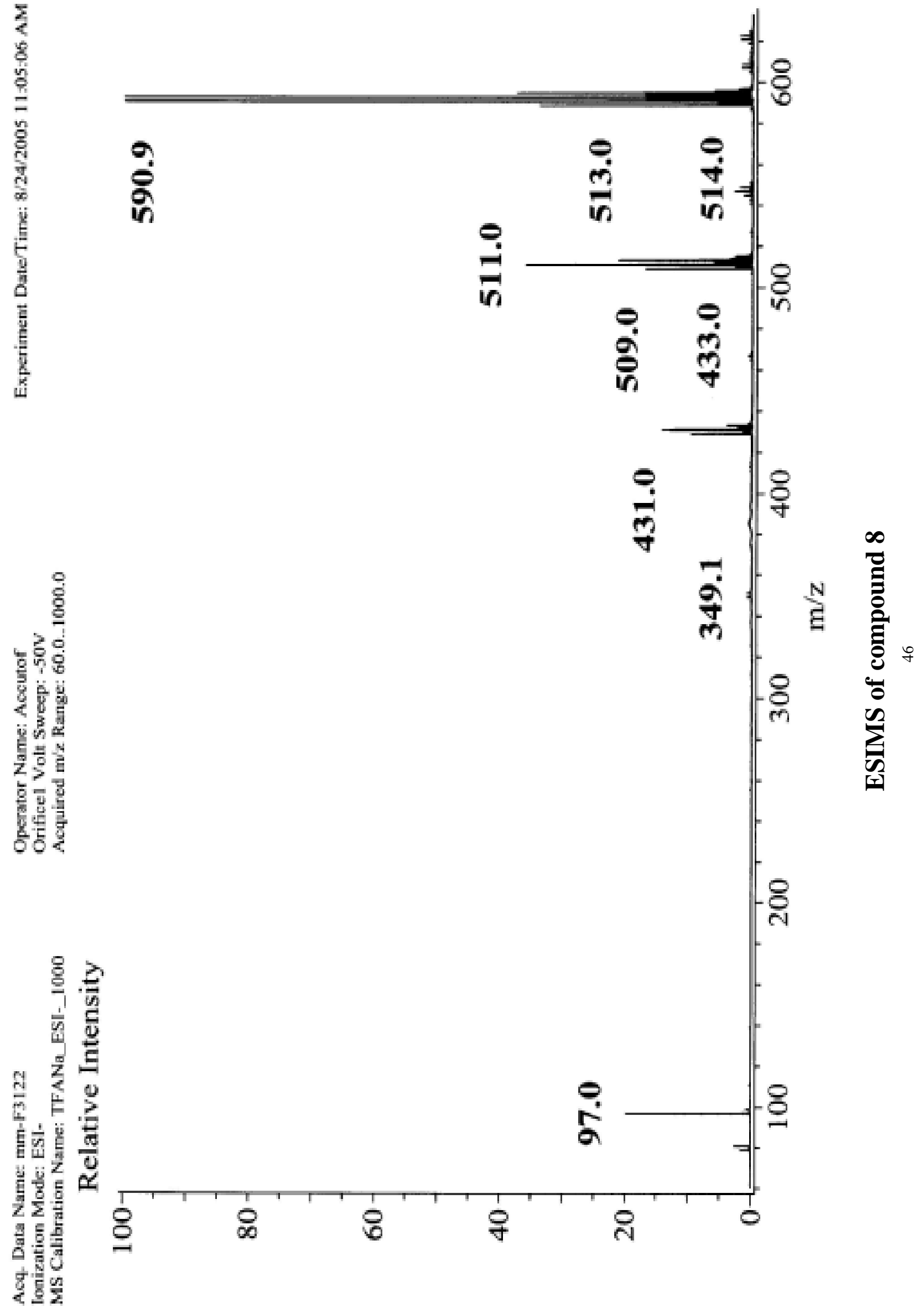


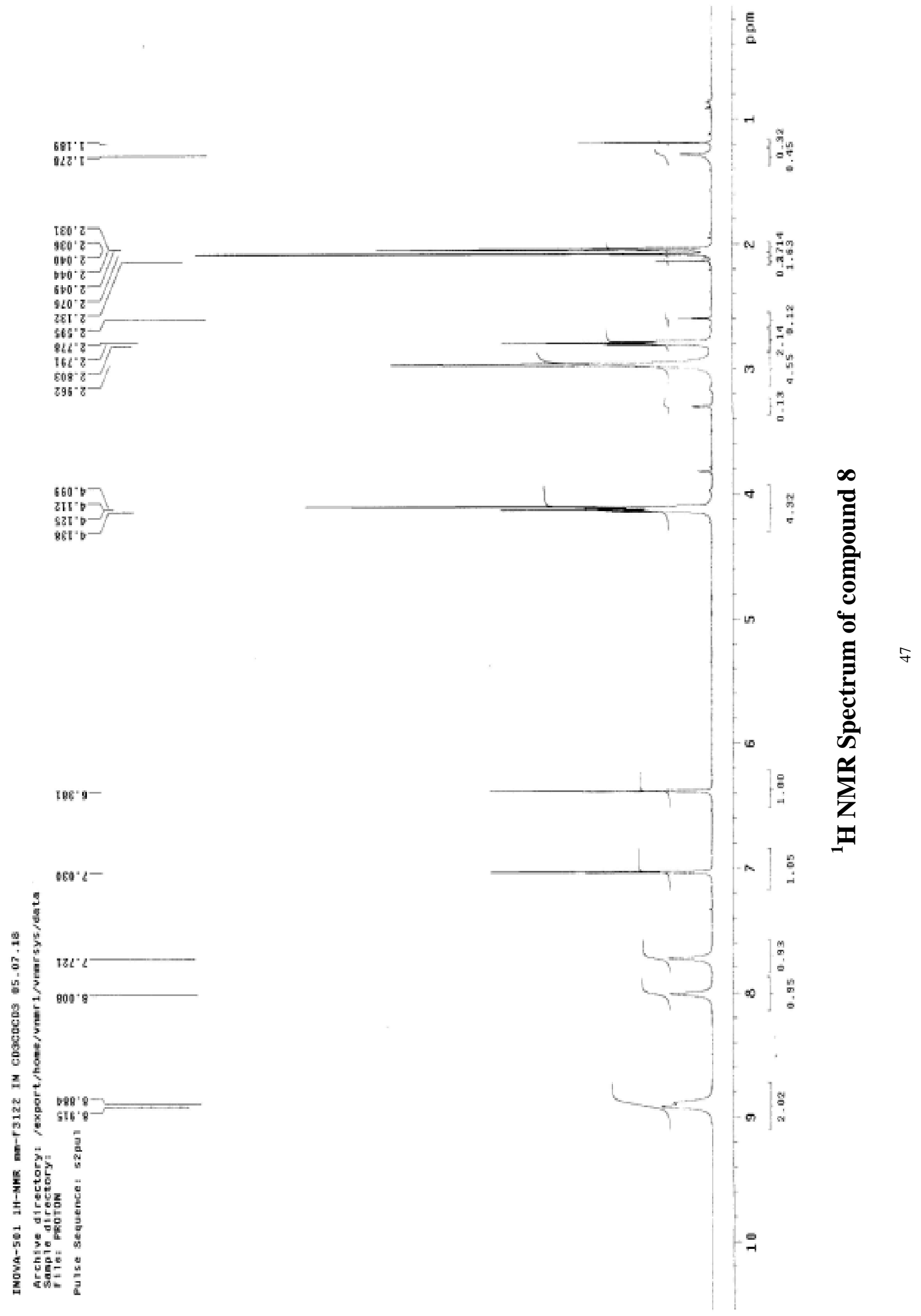




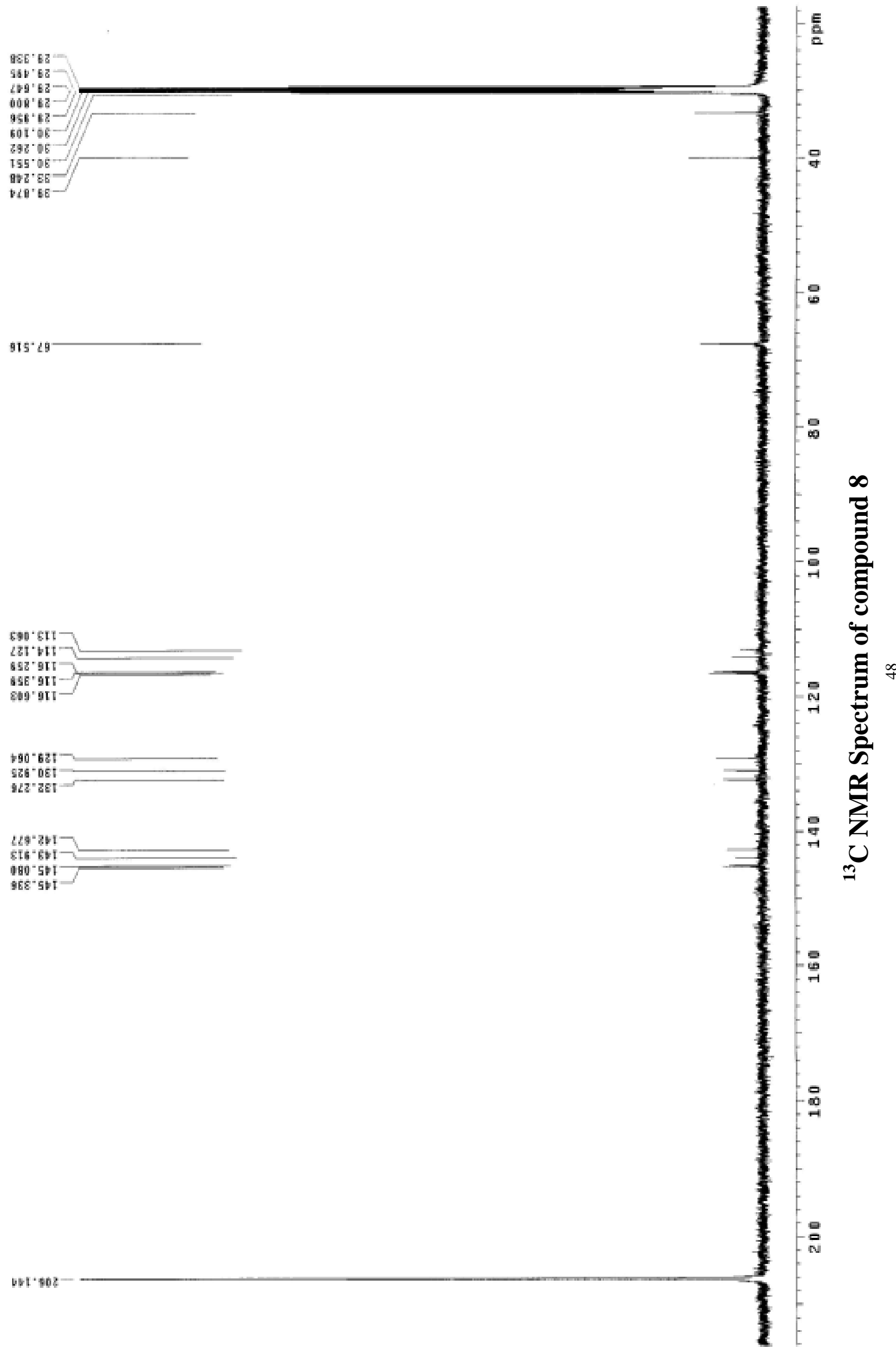



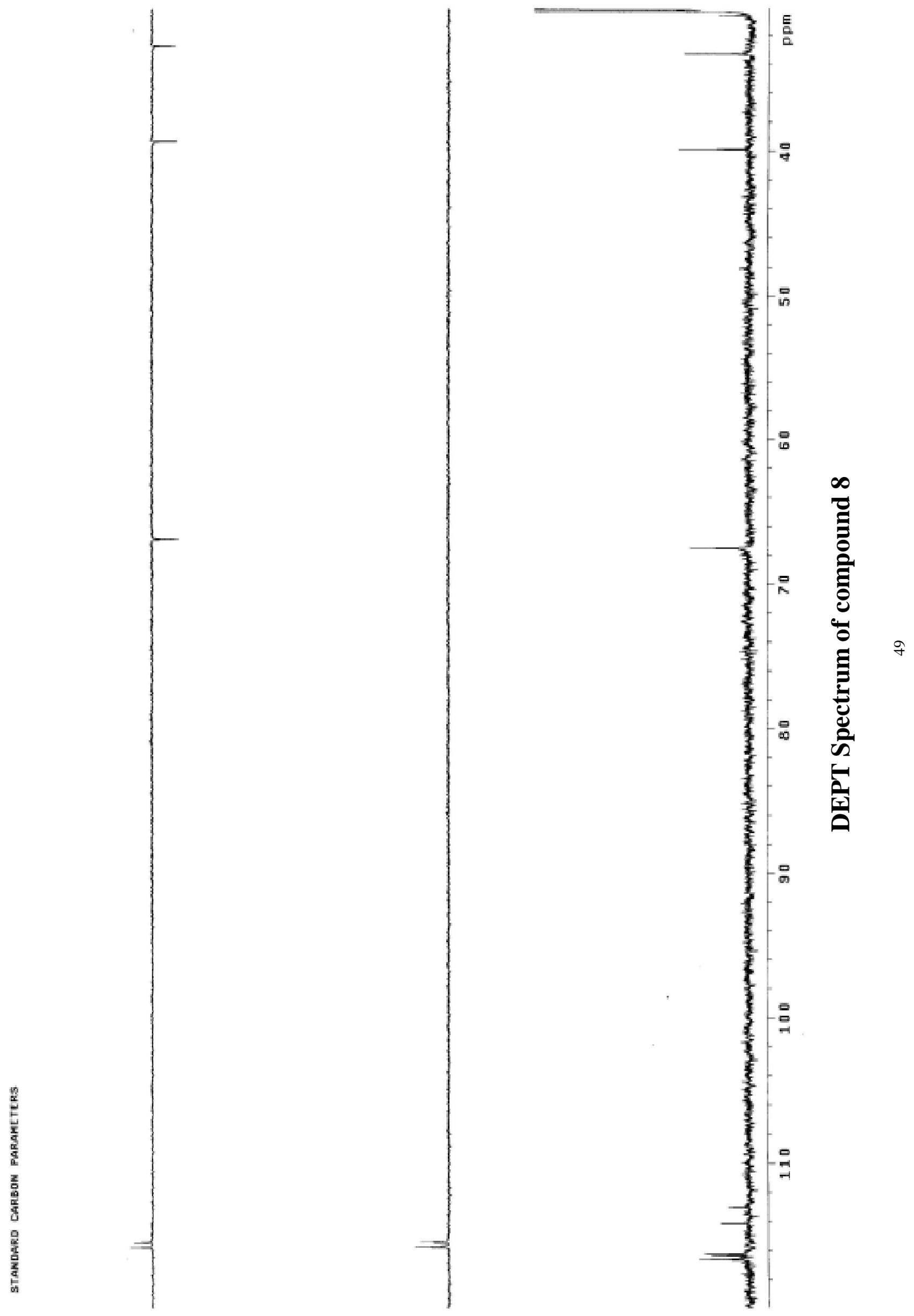


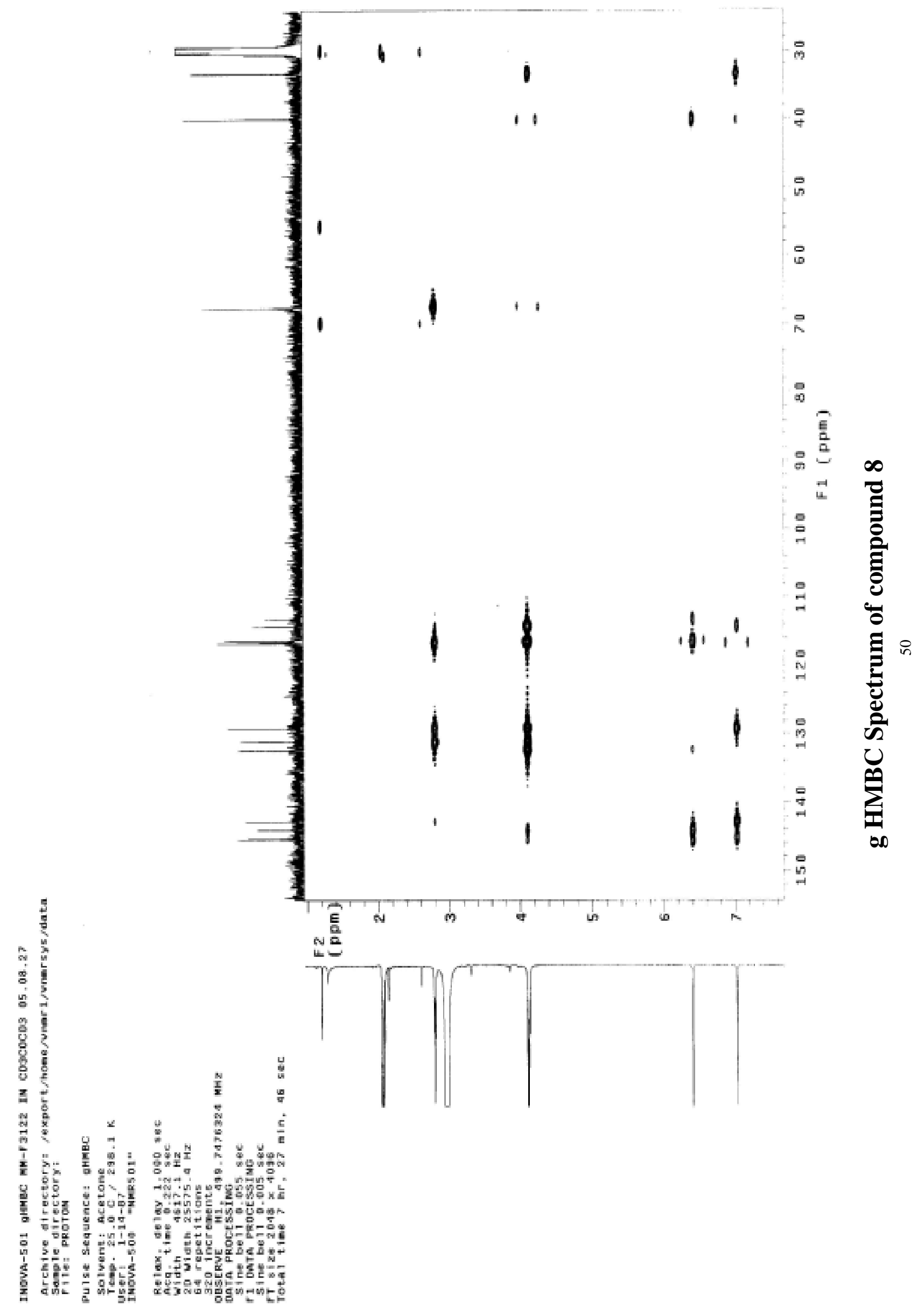

